\title{
Challenging Clinically Unresponsive Medullary Thyroid Cancer: Discovery and Pharmacological Activity of Novel RET Inhibitors.
}

Valeria La Pietra, ${ }^{1 \S}$ Stefania Sartini, ${ }^{2 \S}$ Lorenzo Botta, ${ }^{3 \S}$ Alessandro Antonelli, ${ }^{4}$ Silvia Martina Ferrari, ${ }^{4}$ Poupak Fallahi, ${ }^{4}$ Alessio Moriconi, ${ }^{5}$ Vito Coviello, ${ }^{2}$ Luca Quattrini, ${ }^{2}$ Yi-Yu Ke, ${ }^{6}$ Hsieh Hsing-Pang, ${ }^{6}$ Federico Da Settimo, ${ }^{2}$ Ettore Novellino, ${ }^{1}$ Concettina La Motta,${ }^{2 *}$ and Luciana Marinelli ${ }^{1 *}$

${ }^{1}$ Dipartimento di Farmacia, Università di Napoli "Federico II", Via D. Montesano 49, 80131 Napoli, Italy.

${ }^{2}$ Dipartimento di Farmacia, Università di Pisa, Via Bonanno 6, 56126 Pisa, Italy.

${ }^{3}$ Biological and Ecological Sciences Department, University of Tuscia, Viterbo 01100, Italy. ${ }^{4}$ Dipartimento di Medicina Clinica e Sperimentale, Università di Pisa, Via Savi 10, 56126 Pisa, Italy.

${ }^{5}$ Department of Discovery, Dompé SpA Research Center, 67100 L'Aquila, Italy.

${ }^{6}$ Institute of Biotechnology and Pharmaceutical Research, National Health Research Institutes, 35, Keyan Road, Zhunan Town, Miaoli County 350, Taiwan.

Corresponding Author

* For L.M.: phone, 0039-328-6795645; E-mail, lmarinel@unina.it

* For C.L.M.: phone, 0039-050-2219593; Email, concettina.lamotta@unipi.it

\section{HIGHLIGHTS}

- A tailored ligand-based filtering step generated an heterogeneous focused library

- Twenty-two compounds selected from a VS campaign were found active against RET

- Compound 5 efficiently inhibits the wild type and also the V804L mutant RET kinase

- Compound 5 greatly reduces proliferation of Medullary thyroid carcinoma cells 


\section{ABSTRACT.}

It is now known that "gain of function" mutations of RET (REarranged during Transfection) kinase are specific and key oncogenic events in the onset of thyroid gland cancers such as the Medullary Thyroid Carcinoma (MTC). Although a number of RET inhibitors exist and are capable of inhibiting RET variants, in which mutations are outside the enzyme active site, the majority becomes dramatically ineffective when mutations are within the protein active site (V804L and V804M). Pursuing a receptor-based virtual screening against the kinase domain of RET, we found that compound $\mathbf{5}$ is able to inhibit efficiently both wild type and V804L mutant RET. Compound $\mathbf{5}$ was able to significantly reduce proliferation of both commercially available TT cell lines and surgical thyroid tissues obtained from patients with MTC and displayed a suitable drug-like profile, thus standing out as a promising candidate for further development towards the treatment of clinically unresponsive MTC.

KEYWORDS. Virtual Screening, Docking, Focused library, RET Kinase, Medullary thyroid carcinoma

\section{Introduction}

Medullary thyroid carcinoma (MTC) is a malignant endocrine tumor originating from parafollicular calcitonin-producing C cells. Mainly sporadic (75\% of MTC forms), it may be also present in an inherited form (25\% of cases) as the component of both autosomal-dominant Multiple Endocrine Neoplasia type-2 syndromes and familial medullary thyroid carcinoma (FMTC) [1,2]. At present, the treatment of choice for different forms of MTCs relies in their complete surgical resection. However, disease can persist or recur, with local and distant metastases, and the limited effectiveness of both external beam radiation and conventional cytotoxic agents suggests the need of novel therapeutic strategies [3-6]. 
Recent advances in the knowledge of pathogenic mechanisms leading to MTCs clearly identified the proto-oncogene RET, encoding the homologous receptor tyrosine kinase RET, as the main actor in MTCs development and outbreak. Actually, 'gain of function' mutations and rearrangement of RET activate the kinase activity of the encoded receptor, thus providing mitogenic and survival signals to calcitonin-producing C cells. As mutations in RET have been identified in about $98 \%$ of inherited MTC cases, at the germ-line level, and in $30 \%$ to $50 \%$ of the sporadic cases, at the somatic level, this protein represents a sound target for the molecular therapy of most people affected by MTC [7-10]. Accordingly, a number of small heterocyclic compounds, able to block the kinase activity of RET receptor, have been proposing as a viable therapeutic strategy to treat this pathology. Among them, vandetanib (1, Chart 1) [11] and cabozantinib (2, Chart 1) [12] have been recently approved by both FDA and EMA for the treatment of symptomatic or progressive, advanced and metastatic MTC. Their efficacy is mainly due to the combined blockade of functionally linked and relevant kinases, like RET, VEGFRs, EGFR for vandetanib and MET, VEGFRs, RET, c-KIT for cabozantinib, which in turn lead to the concurrent blockade of pathways active in both tumor parenchyma and stroma [13]. However, although survival gains associated with these inhibitors are clear, their use is not devoid of mild to heavy toxicities, and treatment discontinuation is often required [6].

Moreover, in the case of vandetanib, the ability to inhibit all the RET variants harbouring mutations outside the enzyme active site, like M918T, E768D, L790F, Y791F, A883F, dramatically fades out when a mutation affects the protein active site, like in the V804L and V804M variants. However, vandetanib resistance to V804 alteration is not surprising. Actually, from a structural point of view, V804 in the RET backbone corresponds to the gate-keeper residues of different kinases like Abl, PDGFR, c-KIT, and EGFR, and mutations at these residues are known to confer resistance to a large number of inhibitors [14].

In fact, besides vandetanib, almost all the known RET inhibitors have been demonstrated to be ineffective when the V804L mutation occurs [13]. Accordingly, novel compounds able to block the kinase activity of RET are urgently needed to strike effectively this protein in all its mutant forms, 
especially the V804L and V804M variants which have been recently classified as those conferring a high risk of poor clinical course and survival $[15,16]$.<smiles>COc1cc2c(Nc3ccc(Br)cc3F)ncnc2cc1OCC1CCN(C)CC1</smiles>

1, Vandetanib<smiles>COc1cc2nccc(Oc3ccc(NC(=O)C4(C(=O)Nc5ccc(F)cc5)CC4)cc3)c2cc1OC</smiles>

2, Cabozantinib<smiles>Clc1ccc(SCc2n[nH]c(-c3ccc(Cl)cc3)n2)cc1</smiles>

5, DP01920<smiles>[R]c1ccc([X]c2n[nH]c(-c3ccc([R])cc3)n2)cc1</smiles>

Chart 1. Chemical Structures of RET Inhibitors

Herein, we present the discovery of novel RET inhibitors by means of a receptor-based virtual screening campaign inclusive of a Receptor-Ligand-interaction-based filtering step that allowed us to reach a hit rate of $\sim 50 \%$. Moreover, we succeeded in discovery a novel heterocyclic compound, 5-(4chlorophenyl)-3-((4-chlorophenylthio)methyl)-1H-1,2,4-triazole, (DP01920, compound 5, Chart 1), which proved to inhibit efficiently both wild type and V804L mutant RET and showed a significant antitumor activity against both commercially available TT cell lines and primary cell lines obtained from surgical thyroid tissues of patients with MTC. Investigated for its physical-chemical and pharmacokinetic properties, compound $\mathbf{5}$ displayed a suitable drug-like profile, thus standing out as a promising candidate to develop for the treatment of clinically unresponsive MTC. Accordingly, a number of parent compounds of $\mathbf{5}$ were designed and synthesized, characterized by different linker moieties connecting its main liphophilic areas and bearing distinctive substitution patterns in both 
positions 3 and 5 of the heterocyclic core. Functional evaluation of the novel derivatives helped to sketch out the key structural fragments of RET molecular recognition, which were corroborated and rationalized through molecular docking simulations.

\section{Results and Discussion}

Building up the Filter for the Virtual Screening. From a structural point of view, RET kinase domain consists of two lobes, $\mathrm{N}$ and $\mathrm{C}$, connected through a hinge region. The cleft between the lobes forms the highly flexible active site where the ATP binds. As happens for other kinases, in the RET hinge region, two H-bond acceptors (herein referred as "UP" and "DOWN", and a donor ("MIDDLE") are present (Figure 1A). As highlighted by Dubinina and co-workers [17], known tyrosine kinase inhibitors are able to form at least one H-bond with the MIDDLE spot with the majority of them (87\% of the kinase inhibitor database from MDDR) establishing an additional Hbond either with the UP or the DOWN counter-group of the hinge backbone (these two patterns of H-bonds interactions are herein named 2-UP and 2-DOWN, Figures $1 \mathrm{~b}$ and 1c, respectively). Occasionally, the inhibitor scaffold is even able to establish three H-bonds (TRIPLE pattern, Figure 1d). 


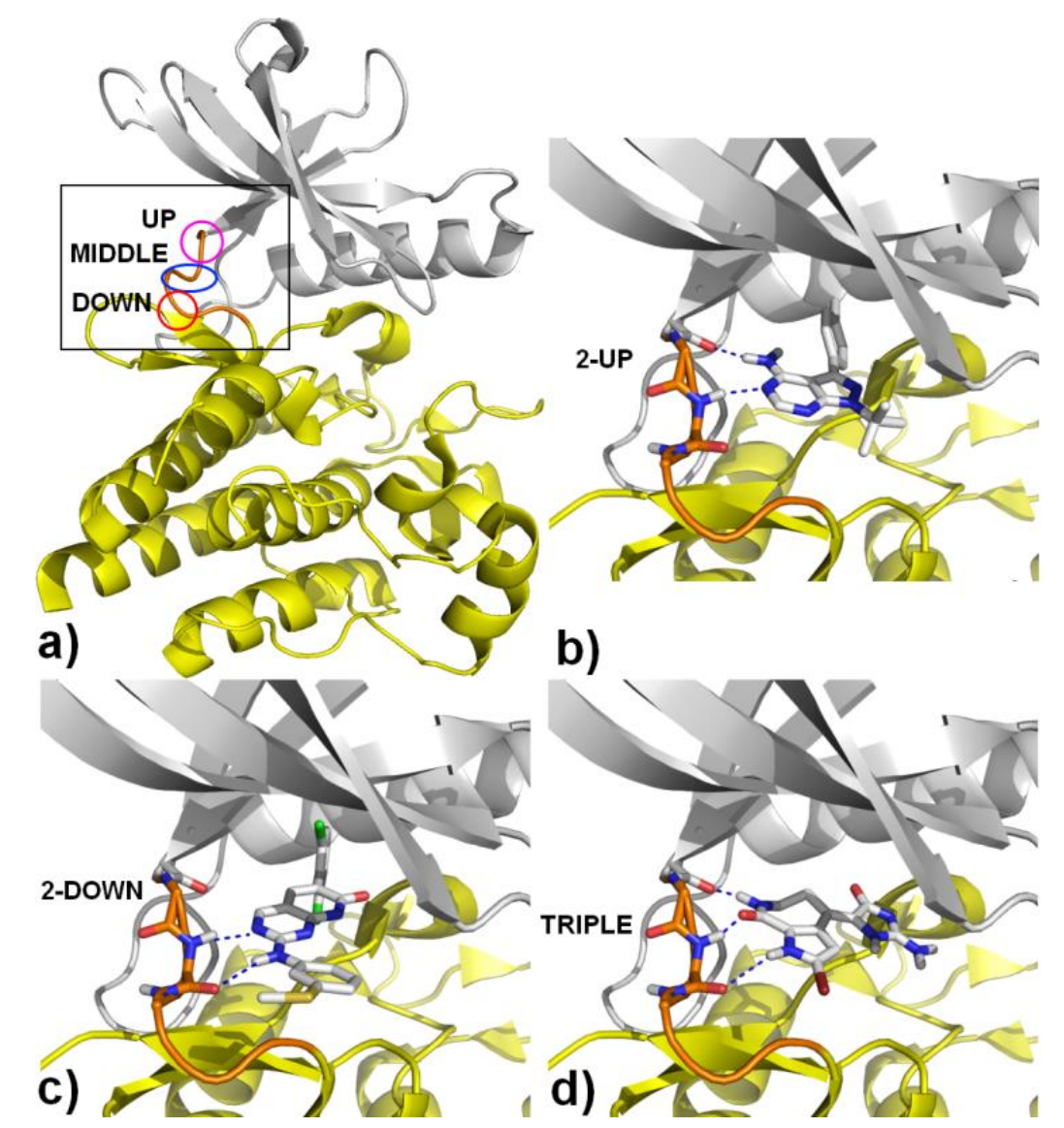

Figure 1. a) Representation of the RET kinase catalytic domain: the N-lobe, the C-lobe and the hinge region are in grey, yellow and orange ribbon, respectively. The rectangular selection highlights the hinge region with its three H-bonding zones: up, middle and down. In b, c, and d, prototypes of RET inhibitors establishing a 2-UP, 2-DOWN and TRIPLE interaction patterns are shown. Specifically, the PP1, PD-173955 and Hymenialdisine inhibitors are depicted in panels b, c, and d, respectively.

Accordingly, in an attempt to reduce the false positives coming from a conventional VS approach, as well as the number of compounds to be actually screened, we filtered the Maybridge Hit Finder Data Base retaining just any scaffolds potentially able to form two H-bonds with the hinge region, namely having an H-bond donor and acceptor within 3-7 bonds distance ("hinge filter", see Figure 2) [17]. 


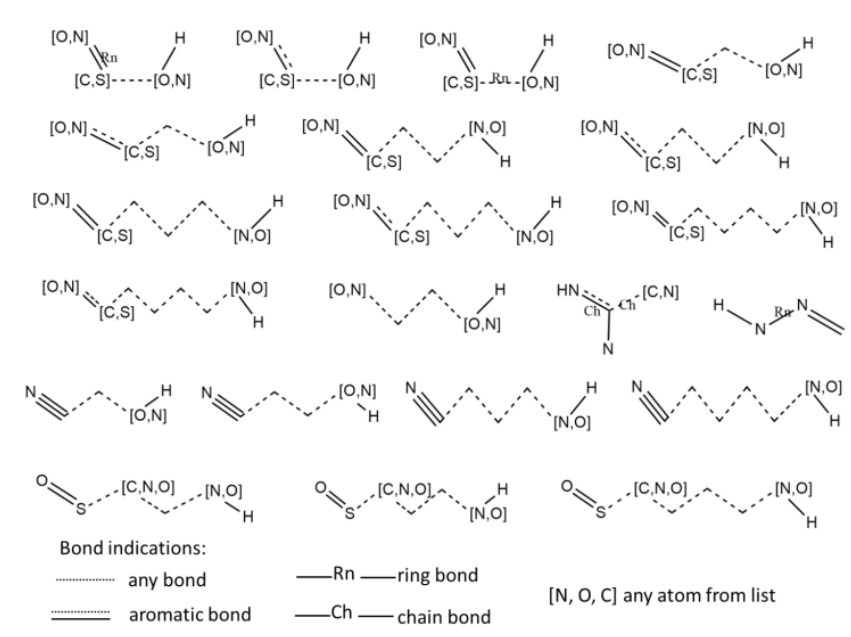

Figure 2. Representation of 2D structural filters used to refine the Hit Finder Maybridge database

Importantly, such a filter permitted to reduce the number of compounds to be screened from 14,400 to 6,248 without compromising the chemical heterogeneity of the database. In this regard, the molecular similarity between the compounds of our collection has been evaluated on the base of the Tanimoto coefficient (MOLPRINT2D2D fingerprint type) [18] with the aid of the "Canvas Similarity and Clustering" tool of the Schrodinger package [19]. Table 1 shows the percentage of compounds within different Tanimoto cutoffs, ranging from 0.01 (minimal similarity) to 0.99 (maximum similarity). Interestingly, the $11,86 \%$ of the molecules possess a Tanimoto similarity index smaller than 0.01 , and more than the $90 \%$ smaller than 0.05 . These numbers indicate that the molecules enclosed in our focused library are certainly very dissimilar and a large variety of chemical chemotypes could possibly be exploited by the virtual screen. For comparison, also some commercially available kinase-focused databases have been analysed: Life Chemical Kinase (LCK) Docking, LCK Similarity, Asinex "Type I", Chembridge KINACore and Chembridge KINASet. Looking at Table 1 and considering, for example, the Tanimoto cutoff of 0.05 , it emerges that the $94,7 \%$ of our molecules are included, while the commercial databases show a percentage of compounds of $28.8 \%, 32.8 \%, 14.7 \%, 62.2 \%$ and $24.5 \%$ respectively. In line with published studies $[20,21]$, the data herein reported highlight a certain correlation between the filtering procedure and the scaffold redundancy: better results in terms of diversity are obtained when using 3D pharmacophore matching (compare KINACore and LCK Similarity) and large queries set (compare 
KINACore and KINASet or LCK Similarity and KINASet). However, it is evident that none of these libraries possess the same level of chemical heterogeneity than ours and that the molecular descriptors used in this work are not biased toward known molecular substructures.

Finally, this focused library, prepared on the base of the kinase-inhibitor interactions pattern, might be potentially screened on every 3D kinase structure representing an universal tool in the kinase inhibitor discovery process.

Table 1. Percentage of Compounds at different Tanimoto Coefficients Cutoff ${ }^{\mathrm{a}}$

\begin{tabular}{|c|c|c|c|c|c|c|}
\hline $\begin{array}{c}\text { Tanimoto } \\
\text { cutoff }\end{array}$ & $\begin{array}{c}\text { Hinge Filter } \\
\text { Database } \\
\mathbf{( 6 2 4 8 )}\end{array}$ & $\begin{array}{c}\text { LCK } \\
\text { Docking } \\
\mathbf{( 1 3 8 0 3 )}\end{array}$ & $\begin{array}{c}\text { LCK } \\
\text { Similarity } \\
\mathbf{( 2 6 7 1 )}\end{array}$ & $\begin{array}{c}\text { Asinex } \\
\text { “Type I" } \\
\mathbf{( 8 7 7 1 )}\end{array}$ & $\begin{array}{c}\text { Chembridge } \\
\text { KINACore } \\
\mathbf{( 1 2 2 5 4 )}\end{array}$ & $\begin{array}{c}\text { Chembridge } \\
\text { KINASet } \\
\mathbf{( 1 0 9 9 3 )}\end{array}$ \\
\hline$<\mathbf{0 . 0 1}$ & 11.9 & 0.4 & 0.04 & 0 & 0.5 & 1 \\
\hline$<\mathbf{0 . 0 2}$ & 28.3 & 2.1 & 1.8 & 0.01 & 5.5 & 2.8 \\
\hline$<\mathbf{0 . 0 3}$ & 54.1 & 7.5 & 7 & 0.6 & 16.7 & 6.1 \\
\hline$<\mathbf{0 . 0 5}$ & 94.7 & 28.8 & 32.8 & 14.7 & 62.2 & 24.5 \\
\hline$<\mathbf{0 . 1}$ & 100 & 95.7 & 97.2 & 98.3 & 100 & 75.5 \\
\hline$<\mathbf{0 . 5}$ & 100 & 100 & 100 & 100 & 100 & 100 \\
\hline$<\mathbf{0 . 9 9}$ & 100 & 100 & 100 & 100 & 100 & 100 \\
\hline
\end{tabular}

${ }^{a}$ The Tanimoto values were calculated using a $\mathrm{n} \times \mathrm{n}$ matrix (all compounds from set compared to one another). The number in parentheses indicates the total number of compounds for each database.

Receptor-Based VS. Docking-based virtual screening was then carried out within the Glide software on the active conformation of RET (PDB code 2IVV [22], see Materials and Methods for the choice criteria). Noteworthy, differently from other kinases, in which the active and the inactive forms show different conformations, in the case of RET, X-ray analysis demonstrated that the non-phosphorylated and phosphorylated forms show the same interlobe orientation, characteristic of the active tyrosine kinases, and have essentially identical A-loop conformations [22]. Thus, targeting the RET active conformation should provide ligands which bind both phosphorylated and non-phosphorylated forms, as already observed for vandetanib [22].The best 1000 hits (in terms of free energy of binding, see Table SI1), as resulted from VS, were subjected to a careful visual inspection of the predicted binding poses in which, as expected, all the compounds were able to establish at least two H-bonds with the RET hinge region (E805, Y806, A807). The predicted binding modes of these compounds were then analysed and only few molecules were selected on the basis of these criteria i) the ligand proximity 
to the residues known to be important for the conformational motion of the two lobes (e.g. K758 and E775); ii) the ligand ability to form hydrophobic interactions within the buried part of the N-lobe (eg. L772, L779, I788, L790, L802); iii) the shape complementarity of compounds with respect to the RET active site. Forty-four candidates were finally chosen and purchased, to test their inhibitory efficacy against a human recombinant kinase domain of wild type RET. The RET kinase inhibitory activity of the test compounds was determined following a previously reported protocol [23-25], by monitoring the increase in fluorescence resulting from phosphorylation of a peptide substrate, catalysed by the target enzyme in the presence of ATP. Five compounds were discarded, being insoluble in the assay medium, while twenty two, out of the remaining thirty nine, proved to inhibit the target protein when tested at a concentration of $100 \mu \mathrm{M}$ (hit ratio of 56.4\%; Table 2 and Table SI2), with fourteen molecules displaying more than $50 \%$ of inhibition at $100 \mu \mathrm{M}$ (final hit ratio of $36 \%$ ). Thus, the experimental success rate obtained in our VS campaign is above the 20-30\% generally obtained when a VS conventional protocol is used. Remarkably, four compounds, 3-6 (Table 2), showed $\mathrm{IC}_{50}$ values against the target protein in the lower micromolar range. Due to the known importance of $\mathrm{RET}^{\mathrm{V} 804 \mathrm{~L}}$ in the clinically unresponsive MTC, the efficacy of derivatives 3-5 against the mutant protein was tested as well. Notably, compounds $\mathbf{3}$ and $\mathbf{5}$ proved to inhibit also the mutated form, being 5 almost equally potent on both wild type and $\mathrm{RET}^{\mathrm{V} 804 \mathrm{~L}}$.

Table 2. Structure, Maybridge Codes and Inhibitory Activity of Test Compounds 3-6.

\begin{tabular}{|c|c|c|c|c|c|c|}
\hline $\mathbf{N}^{\circ}$ & Compound Structure & Code & $\begin{array}{c}\text { wt-RET } \\
\left(\text { IC }_{50}\right)^{a}\end{array}$ & $\begin{array}{c}\text { RET V804L }^{\mathbf{L}} \\
\left(\text { IC }_{50}\right)^{\mathrm{a}}\end{array}$ & $\begin{array}{c}\text { VEGFR2 } \\
\left(\text { IC }_{50}\right)^{\mathrm{a}}\end{array}$ & $\begin{array}{l}\text { EGFR } \\
\left(\text { IC }_{50}\right)^{\mathrm{a}}\end{array}$ \\
\hline 3 & & HTS04502 & 6.16 & 66.2 & 51.6 & n.a. ${ }^{b}$ \\
\hline 4 & & JFD01063 & 6.47 & n.a. ${ }^{b}$ & n.a. ${ }^{b}$ & n.a. ${ }^{b}$ \\
\hline
\end{tabular}




\begin{tabular}{|l|l|l|l|l|l|l|}
\hline 5 & SEW04666 & 9.4 & & & \\
\hline
\end{tabular}

${ }^{\mathrm{a}} \mathrm{IC}_{50}$ values $(\mu \mathrm{M})$ represent the concentration required to produce $50 \%$ enzyme inhibition. Values are the average from at least two independent dose-response curves. Standard error of the mean (SEM) are $\leq 10 \%$. ${ }^{\text {}}$ Not active. No inhibition was observed up to $100 \mu \mathrm{M}$ of the test compound. ${ }^{\mathrm{c}} \mathrm{Not}$ tested.

The observed inhibitory profile of $\mathbf{5}$ was clarified through an additional docking study, performed comparing its binding modes to the active sites of both wild type and V804L mutated protein. As highlighted in Figure 3, compound 5 establishes two H-bonds with the hinge backbone through its triazole ring (in both the $1 \mathrm{H}-1,2,4-$ and $2 \mathrm{H}-1,2,4$ - tautomeric forms, see also Figure SI1). The $p$-Clphenyl ring of the tested compound is able to hold different positions thanks to the presence of the flexible thio-methyl linker, thus it can easily shift its profitable interactions established with L779 and L802 side chains of the wild type protein (Figure 3a) to the hydrophobic contacts with V738 and L881 side chains in the case of RET ${ }^{\text {V804L }}$ (Figure 3b). 


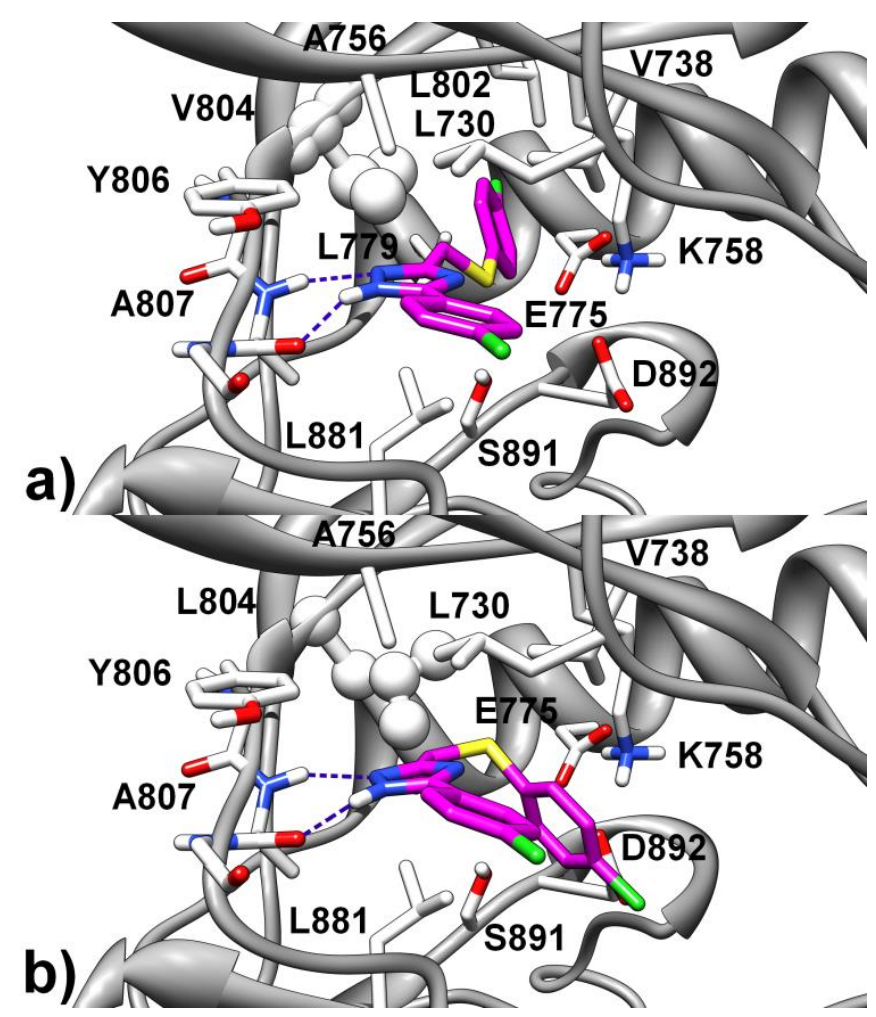

Figure 3. Binding mode of compound 5 into the catalytic domain of WT (a) and V804L mutant (b) RET kinase. The ligand is depicted in magenta sticks. Enzymes are represented in grey ribbons, while the interacting residues are shown as white sticks. V804 and L804 are shown as balls and sticks.

Functional evaluation of compound 5. As 5 turned out to be the most promising candidate among the identified hits, its functional efficacy was deepened through in vitro studies, to highlight both its inhibitory profile and its anti-tumor efficacy. Investigated against other relevant kinases, compound 5 proved to inhibit VEGFR-2 and -3, EGFR and PDGFR- $\beta$, thus showing a remarkably favorable activity (Table 2 and Figure 4). Actually, over-expression of VEGFRs, together with a constitutively activated RET, have been shown to be present in MTC tissues, thus making these proteins primary targets in the treatment of MTCs [26]. Moreover, it has been demonstrated that a combined inhibition of both PDGFR- $\beta$ and VEGFR signaling is very efficacious even in late-stage cancers, disrupting the established tumor vasculature and effecting tumor regression [27]. 


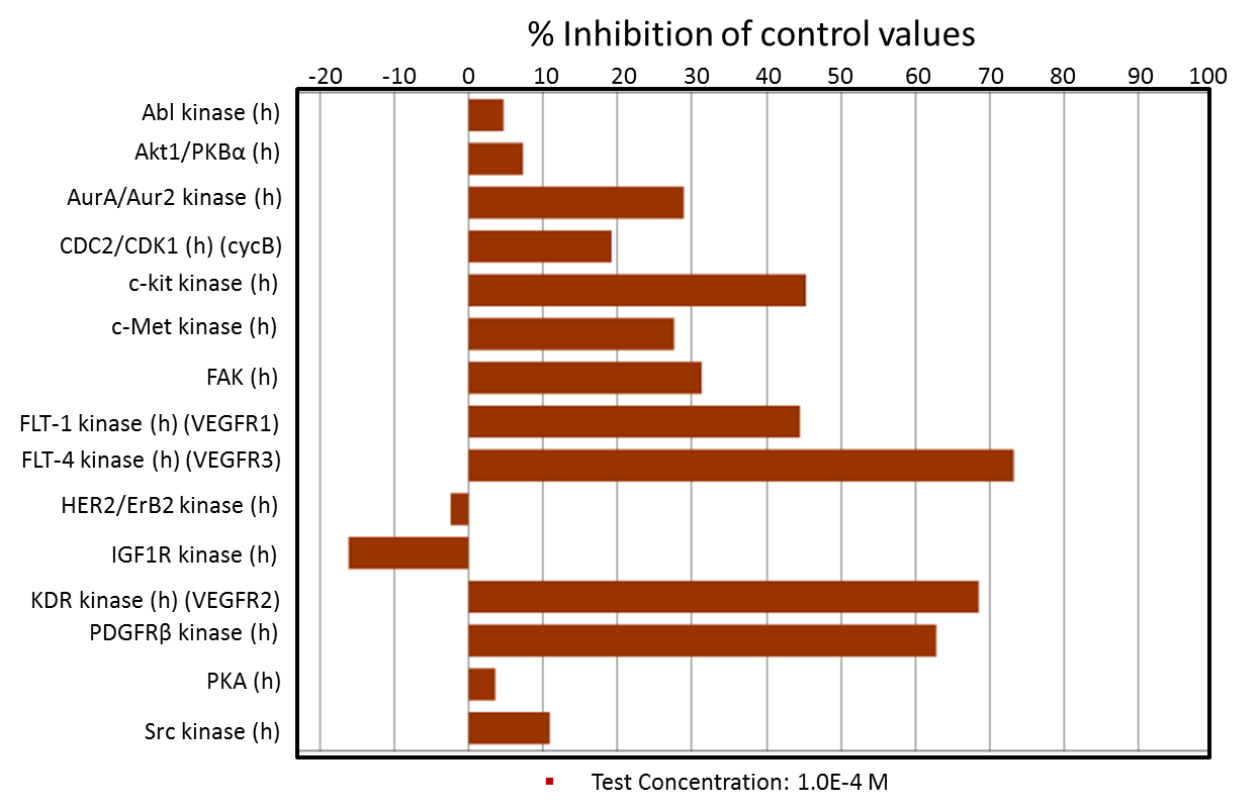

Figure 4. Kinase selectivity profile of compound 5 .

The anti-tumor efficacy of $\mathbf{5}$ was tested on commercially available TT cell lines, derived from human MTC and representing the most reliable model system for the parafollicular C cells available to date [28]. Moreover, $\mathbf{5}$ was also tested on surgical thyroid tissues, obtained from five patients with MTC at the time of surgery, to establish its efficacy on primary cell cultures. As regards the TT cell lines, the viability and proliferation assays (Cell Proliferation Reagent WST-1) were used to assess the number of viable cells. The results highlighted that, when TT cells were treated with 5, 30 and $50 \mu \mathrm{M}$ of compound $\mathbf{5}$, a reduction of proliferation with respect to the control both at $1 \mathrm{~h}$ (data not shown) and at $2 \mathrm{~h}$ was observed (Figure 5), mainly with $30(\mathrm{P}=0.001$, by ANOVA) and $50 \mu \mathrm{M}(\mathrm{P}<0.0001$, by ANOVA). Results observed with surgical thyroid tissues, obtained from the five patients with MTC, provided comparable results (Figure 6). Notably, among the five MTC specimens, two RET mutations were observed (C634G, C634R, respectively). Results about the inhibition of proliferation, obtained in primary MTC cell cultures with RET mutation, were not statistically different from those obtained in MTC without RET mutations (data not shown). Unfortunately, the V804L mutation was not found in none of the selected patients, thus available data are limited to in vitro tests (Table 2). 


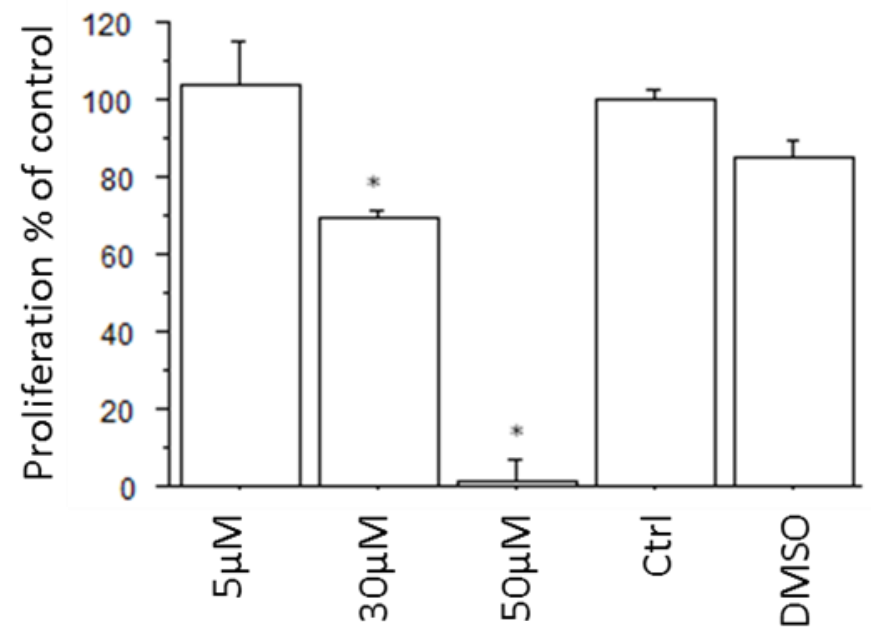

Figure 5. Results of WST-1 assay (mean \pm S.E.M. of all samples at $2 \mathrm{~h}$ from the start of tetrazolium reaction) showed a significant reduction of proliferation (after $48 \mathrm{~h}$ of incubation) with respect to the control (Ctrl) with 5 at 30 and $50 \mu \mathrm{M}(\mathrm{P}<0.05$, by ANOVA) in TT cells. Bars are mean \pm S.E.M. *P $<0.05$ or less versus Ctrl by Bonferroni-Dunn test.

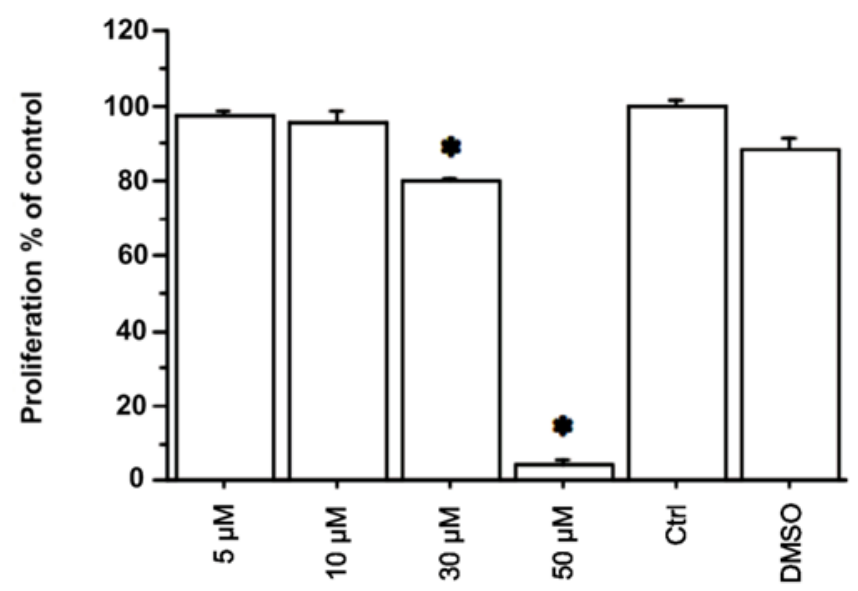

Figure 6. Results of WST-1 assay (mean \pm S.E.M. of all samples at $2 \mathrm{~h}$ from the start of tetrazolium reaction) showed a significant reduction of proliferation (after $48 \mathrm{~h}$ of incubation) with respect to the control (Ctrl) with 5 at 30 and $50 \mu \mathrm{M}$ in primary medullary thyroid cancer cells. Bars are mean \pm S.E.M. *P $<0.05$ or less versus Ctrl by Bonferroni-Dunn test.

LogD, Metabolic Stability, hERG Theoretical Binding. Prompted by the significant anti-tumour results, we than pursued our studies on $\mathbf{5}$ investigating its physical-chemical properties, metabolic 
stability in plasma and liver microsomes, and potential hERG-related toxicity of the compound, to probe its soundness as novel hit candidate for the treatment of MTCs. The $\log \mathrm{D}$ value was experimentally determined at $\mathrm{pH}=7.4$ and resulted to be within the range of the drug-likeness $\left(\log \mathrm{D}_{7.4}=4.1\right)$ [29]. The thermodynamic solubility turned out to be somewhat low $(1 \mathrm{nM})$, but this limit was profitably overcome by conversion of $\mathbf{5}$ into the corresponding potassium salt, $\mathbf{4 2}$. This latter, obtained treating 5 with $\mathrm{KOH} / \mathrm{EtOH}$, kept unaltered the inhibitory profile and turned out to be equipotent to the parent acid, 5, against the wild type RET (data not shown). Metabolic stability of $\mathbf{5}$ was assessed as well, by using liver human microsomes and human plasma. The test compound showed a good stability in microsomes (40\% of remaining compound after 15 min of incubation at 1 $\mu \mathrm{M})$ and an excellent plasma stability ( $85 \%$ of remaining compound after $1 \mathrm{~h}$ of incubation). Furthermore, $\mathbf{5}$ was predicted not to be an hERG inhibitor by using the rule of thumb of an in silico model recently described [30]. Accordingly, $\mathbf{5}$ should display, in principle, a safe cardiac profile, thus turning out to be more favorable with respect to vandetanib, for which a high rates of hERG-mediated QT interval prolongation has been reported so that FDA required a restricted distribution program [31]. All together, these data indicate that 5 represent a viable hit to optimize.

Structural optimization of compound 5. To identify novel promising lead compounds, we embarked in a structure-guided synthetic campaign exploring the key pharmacophore elements of compound $\mathbf{5}$ and their relevance in the molecular recognition of RET active site.

Leaving unaltered the 1,2,4-triazole core, required to hook the hinge region through H-bond interactions, we first investigated the role of the thio-methyl linker, which was replaced either with an oxy-methyl or an ethyl chain, or even oxidized to a sulfonyl-methyl fragment, as in compounds 43a-c. Then, focusing on the pendant phenyl rings in positions 3 and 5 of the nucleus, different substituents were exploited to replace the chlorine atoms, one at a time, in order to verify the influence of electron-withdrawal, electron-release, steric bulk and orientation on the interaction with both the buried region of the site and the area exposed to the solvent. Accordingly, we designed and synthesized both compounds $\mathbf{4 3 d} \mathbf{- i}$, bearing either electron-withdrawing or electron-releasing groups 
in position para of the 5-phenyl ring, and compounds $\mathbf{4 3} \mathbf{j}-\mathbf{n}$, where the aromatic area in position 3 of the hit was expanded through the insertion of phenyl-ureido, benzamido, and phenyl-sulfonamido fragments.

Chemistry. Derivative 43a, 3-((4-chlorophenoxy)methyl)-5-phenyl-1H-1,2,4-triazole, was obtained as reported in Scheme 1. Reaction of 2-(4-chlorophenoxy)acetonitrile, 44, with benzohydrazide, $\mathbf{4 5}$, in the presence of sodium ethoxide, gave the key intermediate 46, N'-(2-(4-chlorophenoxy)-1aminoethylidene)benzohydrazide, which cyclized to the target inhibitor, 43a, by treatment with $\mathrm{POCl}_{3}$. Compound 43b, 3-(4-chlorophenethyl)-5-(4-chlorophenyl)-1H-1,2,4-triazole, was prepared according to Scheme 2. Treatment of the commercially available ethyl 3-(4-chlorophenyl)propanoate, 47, with hydrazine in methanol solution afforded the corresponding propanehydrazide 48, which was converted into the desired inhibitor $\mathbf{4 3 b}$ by reaction with the commercially available benzamidine hydrochloride 49, in the presence of sodium ethoxide. Derivative 43c, 3-(4-chlorophenyl)-5-(((4chlorophenyl)sulfonyl)methyl)-1H-1,2,4-triazole, was synthesized as depicted in Scheme 3 . The commercial acetohydrazide $\mathbf{5 0}$ was reacted with 4-chlorobenzonitrile $\mathbf{5 1}$, at $150^{\circ} \mathrm{C}$ in a sealed tube and in the presence of $\mathrm{K}_{2} \mathrm{CO}_{3}$, to achieve the 1,2,4-triazole 5 according to the procedure of Yeung and co-workers [32]. Then, 5 was oxidized to $\mathbf{4 3 c}$ by treatment with $m$-chloroperbenzoic acid.

Scheme 1. Synthesis of 3-((4-Chlorophenoxy)methyl)-5-phenyl-1H-1,2,4-triazole, 43a

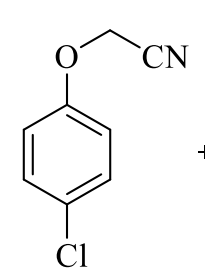

44

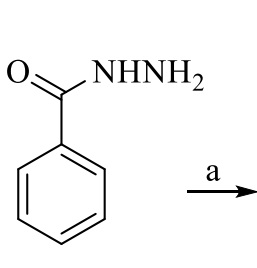

45<smiles>N/C(COc1ccc(Cl)cc1)=N/NC(=O)c1ccccc1</smiles>

a) EtONa, EtOH, reflux, $12 \mathrm{~h}, 25 \%$; b) $\mathrm{POCl}_{3}, 130^{\circ} \mathrm{C}, 8 \mathrm{~h}, 33 \%$. 
Scheme 2. Synthesis of 3-(4-chlorophenethyl)-5-(4-chlorophenyl)-1H-1,2,4-triazole, 43b<smiles>CCOC(=O)CCc1ccc(Cl)cc1</smiles>

47<smiles>N=C(N)c1ccc(Cl)cc1</smiles>

49

a) $\mathrm{NH}_{2} \mathrm{NH}_{2}, \mathrm{MeOH}$, reflux, 2h, $89 \%$; b) EtONa, EtOH, reflux, 8 h, $30 \%$.

Scheme 3. Synthesis of 5-(4-chlorophenyl)-3-(((4-chlorophenyl)sulfonyl)methyl)-1 H-1,2,4-triazole, 43c.<smiles>NNC(=O)CSc1ccc(Cl)cc1</smiles>

50<smiles>N#Cc1ccc(Cl)cc1</smiles>

51<smiles>Clc1ccc(SCc2n[nH]c(-c3ccc(Cl)cc3)n2)cc1</smiles>

$\downarrow b$<smiles>O=S(=O)(Cc1n[nH]c(-c2ccc(Cl)cc2)n1)c1ccc(Cl)cc1</smiles>

a) $\mathrm{K}_{2} \mathrm{CO}_{3}, \mathrm{BuOH}, 150{ }^{\circ} \mathrm{C}, 16 \mathrm{~h}, 51 \%$; b) mCPBA, DCM, rt, 5h, $81 \%$.

Inhibitors 43d-i, keeping unaltered the $p$-chlorophenyl-thiomethyl residue of the hit, were synthesized following a similar procedure (Scheme 4), from acetohydrazide $\mathbf{5 0}$ and commercially available or previously prepared benzonitriles (52a-f, Supporting Information). 
Scheme 4. Synthesis of 5-(4-chlorophenyl)-3-((4-substitutedphenylthio)methyl)-1H-1,2,4-triazoles, 43d-i.<smiles>NNC(=O)CSc1ccc(Cl)cc1</smiles>

50<smiles>[R]c1ccc(C#N)cc1</smiles>

52a-f

a) $\mathrm{K}_{2} \mathrm{CO}_{3}, \mathrm{BuOH}, 150^{\circ} \mathrm{C}, 16 \mathrm{~h}$.

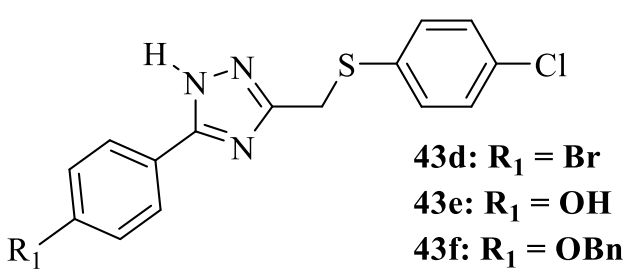<smiles>[131Sn]=[Ru]Oc1ccncc1</smiles>

43h: $\mathrm{R}_{1}=\mathrm{NH}_{2}$ 43i: $R_{1}=$ Methyl-Piperazine

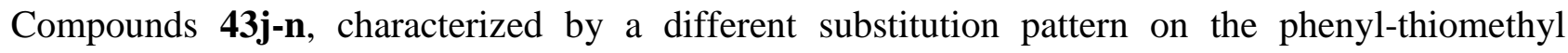
fragment, were obtained as described in Scheme 5. Reaction of 4-aminobenzenethiol $\mathbf{5 3}$ with ethyl chloroacetate and $\mathrm{K}_{2} \mathrm{CO}_{3}$, followed by treatment with hydrazine in methanol solution, gave the intermediate acetohydrazide $\mathbf{5 4}$, which cyclized to the 1,2,4-triazole derivative $\mathbf{5 5}$ by reaction with the suitable benzonitrile, in the presence of $\mathrm{K}_{2} \mathrm{CO}_{3}$. The key 1,2,4-triazole intermediate afforded the ureic inhibitors $\mathbf{4 3 j - I}$ by treatment with differently substituted phenyl isocyanates, the benzamide derivative $43 \mathrm{~m}$ by reaction with benzoyl chloride, and the benzenesulfonamide derivative $43 n$ by using benzenesulfonyl chloride. 
Scheme 5. Synthesis of 5-(4-chlorophenyl)-3-((4-substitutedphenylthio)methyl)-1 H-1,2,4-triazole, 43j-l

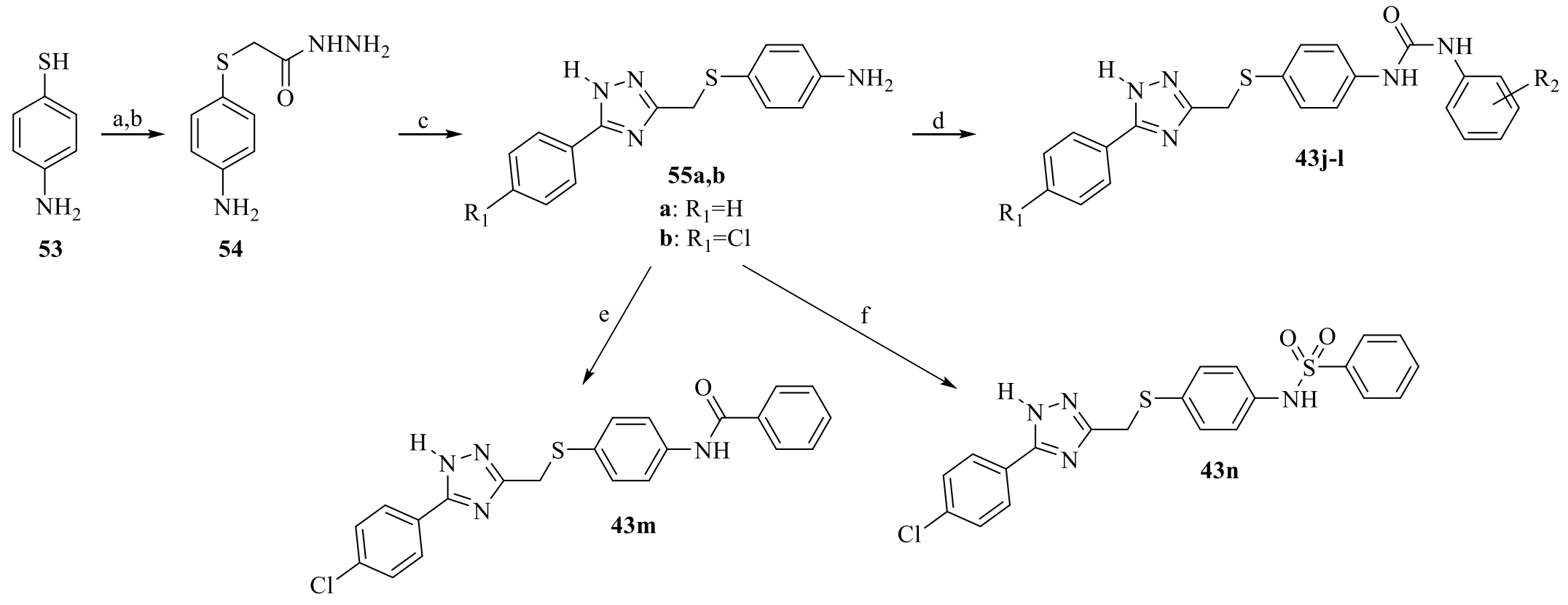

a) $\mathrm{ClCH}_{2} \mathrm{COOEt}, \mathrm{K}_{2} \mathrm{CO}_{3}$, DMF, rt, 2h; b) $\mathrm{NH}_{2} \mathrm{NH}_{2}, \mathrm{MeOH}$, reflux, 2h, 90\%; c) (4-chloro)Benzonitrile, $\mathrm{K}_{2} \mathrm{CO}_{3}, \mathrm{BuOH}, 150{ }^{\circ} \mathrm{C}, 16 \mathrm{~h}, 72 \%$; d) Substituted-phenyl isocyanate, THF, rt, 3h; e) Benzoyl chloride, toluene, rt, 1h, 46\%; f) Benzenesulfonyl chloride, Et ${ }_{3} \mathrm{~N}$, toluene, $\mathrm{rt}, 46 \%$. 
Functional Evaluation of Compounds 43a-n. All the synthesized derivatives were tested for their inhibitory properties against the target protein RET, starting from the reference concentration of 100 $\mu \mathrm{M}$ exploited in the lead off screening study. Compounds 43a-c, featuring different di-atomic linkers connecting the main cyclic portions of the inhibitors, did not show any relevant functional efficacy (Table 3), thus emphasizing the prominent role played by the thio-methyl fragment in the interaction with the active site of the protein. Modification of the $p$-chloro substitution pattern on the 5-phenyl ring of the hit, like in compounds $\mathbf{4 3 d} \mathbf{- i}$, gave rise to contrasting results. Replacing the chloro atom with the bulkier, less electron-attracting bromine one turned out to be detrimental, as the inhibitory activity of the resulting $\mathbf{4 3 d}$ was strongly reduced (Table 3). On the contrary, the presence of the electron-donating hydroxy group, as in derivative 43e, retained an appreciable functional efficacy. Further functionalization of the hydroxy group, performed either with a benzyl residue, as in $\mathbf{4 3 f}$, or with a pyridine ring, like in $\mathbf{4 3 g}$, drastically reduced or even nullified the activity. The aromatic area in position 3 of the 1,2,4-triazole core was then widen through the insertion of phenyl-ureido (43j431), benzamido (43m) and phenyl-sulfonamido (43n) moieties. Among others, the insertion of both a meta-acetyl residue and a dimethoxy substitution on the distal phenyl ring, as in $\mathbf{4 3 k}$ and $\mathbf{4 3 1}$ respectively, allowed to increase the inhibitory potency of the hit.

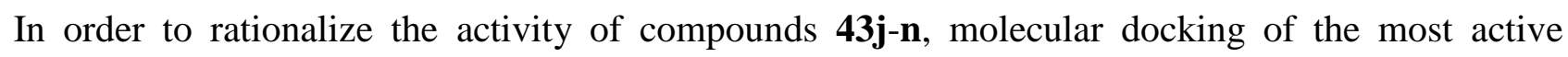
derivative 431 was performed with the aid of the Glide software. The docking calculations clearly suggest that the novel analogue is no longer able to fit the widened aromatic area in position 3 in the buried part of the $\mathrm{N}$-lobe like in the case of $\mathbf{5}$. In fact the program converged toward a pose (Figure 7) where the triazole core, still able to establish two H-bonds with the E805 and the A807 hinge backbone, is flipped so that the $p$-Cl-phenyl ring is oriented toward the N-lobe pocket, while the thiomethyl linker bends in order to direct the extended phenyl-ureido moiety under the nucleotide-binding loop (K728-K737). This pose, already found for other bis-aryl urea kinase inhibitors [33], is stabilized by an H-bond between the catalytic D892 carboxylate and the urea group, and allows the formation of several hydrophobic contacts between the two $\mathbf{4 3 1}$ aromatic rings and the protein (F735, V738, 
L881, L895) and of a cation-pi interaction between the terminal phenyl ring and the K758 side chain, which is strengthened by the two methoxy electron donor groups. The small difference in activity of 43k with respect to 431, may be possibly ascribable to the presence of an electron withdrawing group in this position. Looking at the several RET X-ray complexes available in the PDB (for example 2IVS, 2IVT, 2IVV, 2IVU, 2X2L, 5AMN, 5FM3), it emerges that different ligands can induce a different opening of the nucleotide-binding loop and a displacement of the F735 side chain, crucial events for their accommodation. In particular, bulkier ligands induce a deeper opening. Thus, it is reasonable that the presence of bulky substituents (like two methoxy in $\mathbf{4 3 l}$ and acetyl group in 43k) on the terminal phenyl ring is important for such a conformational change and that not substituted analogues like $\mathbf{4 0 j}$ are inactive because unable to activate a profitable rearrangement for their accommodation.

The results described so far are also in line with the other data of Table 3. In fact, the inactive compounds 43m and 43n, possessing an amido and a sulfonamido group, which are endowed with a different geometry and length with respect to the urea, would not accommodate into the ATP pocket in the same fashion of $\mathbf{4 3 1}$. Indeed, docking of $\mathbf{4 0 m}$, shows that in order to place the amido-aromatic portion under the nucleotide-binding loop, the molecule shifts its position and the two H-bonds with the hinge region are lost (Figure SI2).

These results provide useful and clear clues about the future synthetic development of this class of RET inhibitors. Actually, compounds 43k and 431 clearly point out that substitution on the distal aromatic area in position 3 of the 1,2,4-triazole core could be a valuable staring point to obtain novel and highly potent inhibitors, and that phenyl-ureido moieties substituted with large and polar groups are required in this region. 


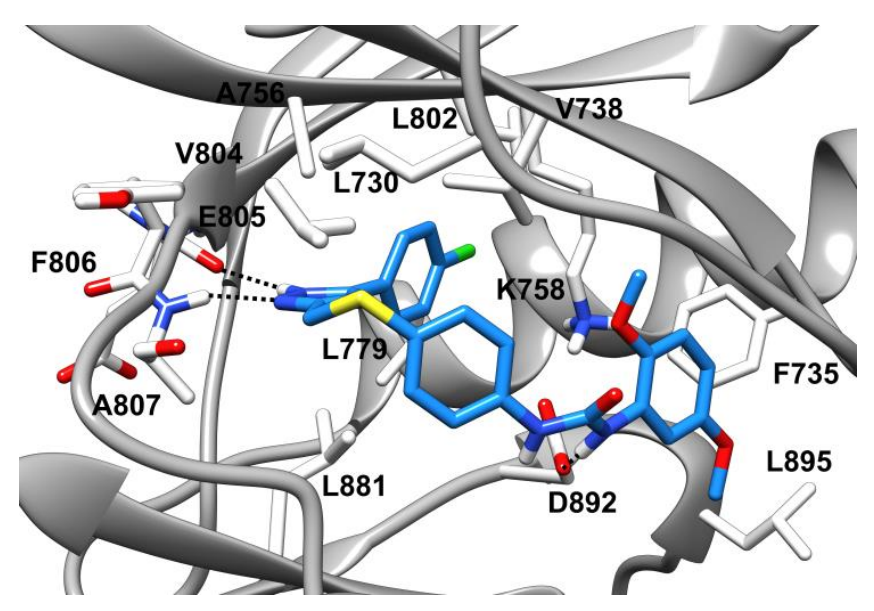

Figure 7. Binding mode of compound 431 into the catalytic domain of WT RET kinase. The ligand is depicted in blue sticks. The protein is represented in grey ribbons, while the interacting residues are shown as white sticks. H-bonds are highlighted in dashed black lines and apolar hydrogens are omitted for sick of clarity.

Table 3. RET Inhibitory Activity of 1,2,4-Triazole derivatives 43a-n.<smiles>[R]c1ccc([X])cc1</smiles>

\begin{tabular}{|c|c|c|c|c|c|}
\hline $\mathbf{N}^{\circ}$ & $\mathbf{X}$ & $\mathbf{R}_{1}$ & $\mathbf{R}_{2}$ & $\begin{array}{c}\text { \% Inhibition } \\
(100 \mu \mathrm{M})\end{array}$ & $\begin{array}{l}\text { IC }_{50}{ }^{\mathbf{a}} \\
(\mu \mathrm{M})\end{array}$ \\
\hline $43 a$ & $\mathrm{O}$ & $\mathrm{H}$ & $\mathrm{Cl}$ & n.a. ${ }^{b}$ & \\
\hline $43 b$ & $\mathrm{CH}_{2}$ & $\mathrm{Cl}$ & $\mathrm{Cl}$ & n.a. ${ }^{b}$ & \\
\hline $43 c$ & $\mathrm{SO}_{2}$ & $\mathrm{Cl}$ & $\mathrm{Cl}$ & n.a. ${ }^{\text {b }}$ & \\
\hline 43d & $S$ & $\mathrm{Br}$ & $\mathrm{Cl}$ & 30 & \\
\hline $43 e$ & S & $\mathrm{OH}$ & $\mathrm{Cl}$ & & 32.5 \\
\hline $43 f$ & S & & $\mathrm{Cl}$ & n.a. ${ }^{b}$ & \\
\hline $43 g$ & $\mathrm{~S}$ & & $\mathrm{Cl}$ & 33.0 & \\
\hline $43 h$ & $S$ & $\mathrm{NH}_{2}$ & $\mathrm{Cl}$ & 45.7 & \\
\hline $43 i$ & $\mathrm{~S}$ & & $\mathrm{Cl}$ & & 19.0 \\
\hline
\end{tabular}




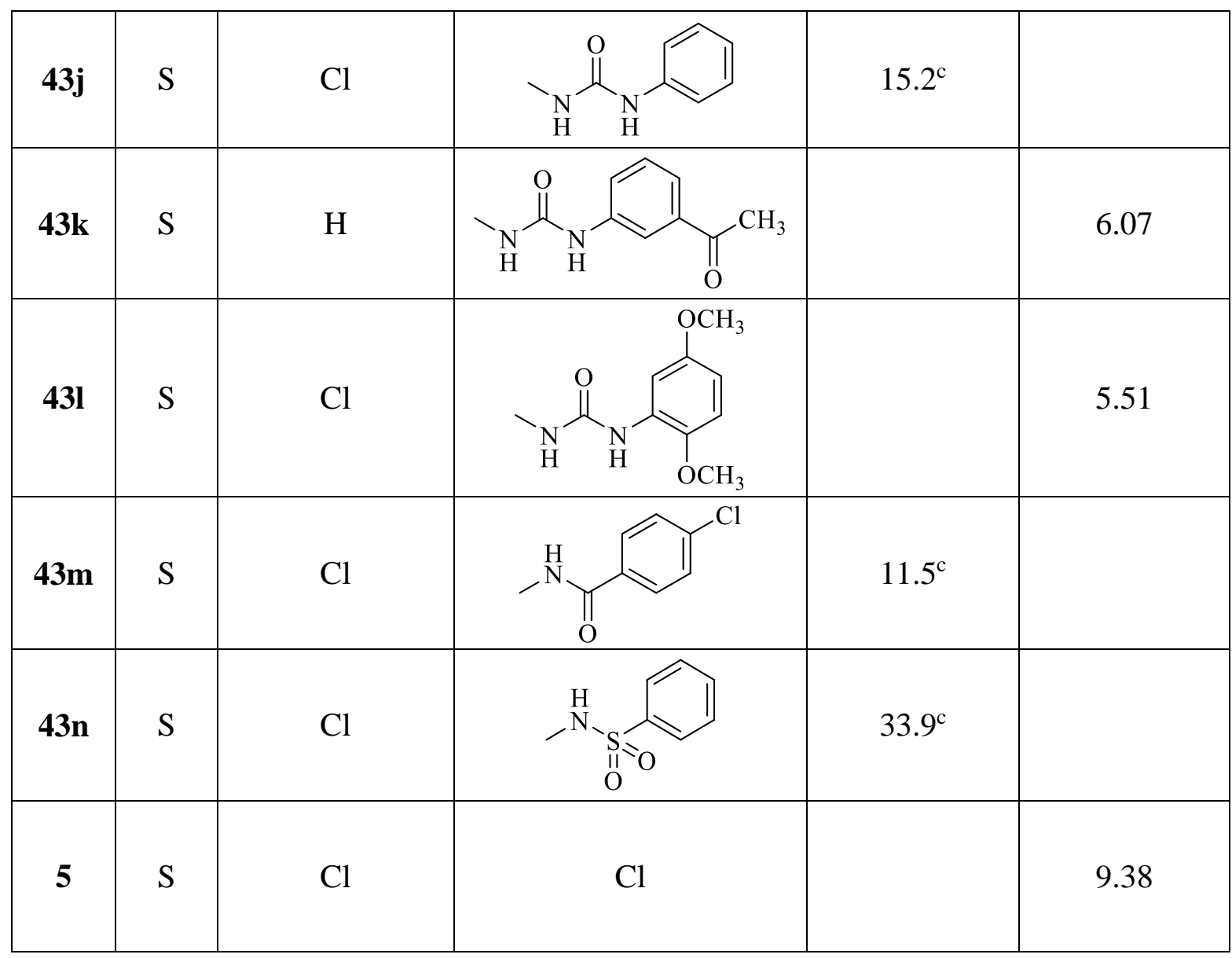

${ }^{\mathrm{a}} \mathrm{IC}_{50}$ values $(\mu \mathrm{M})$ represent the concentration required to produce $50 \%$ enzyme inhibition. Values are the average from at least two independent dose-response curves. Standard error of

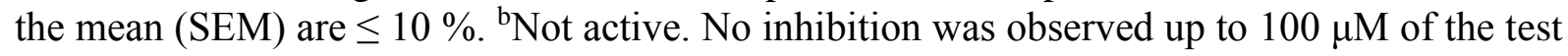
compound. ${ }^{\mathrm{c} C o m p o u n d}$ tested at $10 \mu \mathrm{M}$.

\section{Conclusion}

In this study, a virtual screening campaign was conducted to identify novel RET inhibitors. Particularly, taking advantage of the knowledge regarding the interactions pattern between ATPmimetic inhibitors and the kinase hinge region, we applied a $2 \mathrm{D}$ filtering step that allowed us to reduce the number of molecules to screen and to obtain a focused library where, possibly, a generous number of false positives were removed. Then, this ligand-based procedure was followed by a receptor-based VS on the RET X-ray structure. Through the herein described campaign, twenty-two out of thirty-nine compounds proved to inhibit the target protein yielding an experimental hit ratio higher than the $20-30 \%$ generally obtained by a conventional VS protocol. Moreover, we succeeded in discovering a novel 1,2,4-triazole derivative, $\mathbf{5}$, which proved to inhibit effectively both wild type 
and V804L mutant RET, thus overcoming in principle the problem of resistance displayed by drugs currently approved for MTC, vandetanib and cabozantinib. The combined blockade of RET, EGFR, VEGFR-2 and -3, and PDGFR- $\beta$, all playing a pivotal role in MTC onset and progression, allowed 5 to reduce viability and proliferation of both TT cells and primary cell cultures obtained from surgical thyroid specimens. This functional behavior, together with favourable early ADME properties, made 5 an ideal candidate for a lead optimization campaign. Accordingly, a series of derivatives were synthesized and tested, which helped us to sketch out the key structural fragments for a fruitful RET molecular recognition. Interestingly, derivatives $43 \mathbf{k}$ and 431 , characterized by the widest and most polar substitution pattern on position 3 of the triazole core, turned out to be more active than $\mathbf{5}$, thus paving the way for future structure-activity investigation in this direction.

\section{Materials and Methods}

Chemistry. Melting points were determined using a Reichert Köfler hot-stage apparatus and are uncorrected. Routine ${ }^{1} \mathrm{H}-\mathrm{NMR}$ spectra were recorded in DMSO-d $\mathrm{d}_{6}$ solution on a Varian Gemini 200 spectrometer operating at $200 \mathrm{MHz}$. Evaporation was performed in vacuo (rotary evaporator). Analytical TLC was carried out on Merck $0.2 \mathrm{~mm}$ precoated silica gel aluminium sheets (60 F-254). Flash chromatography was performed on silica gel (70-230 mesh ASTM) using the reported eluents. High-resolution ESI-MS spectra were performed on a Thermo LTQ Orbitrap XL mass spectrometer. Purity of the target inhibitors, 43a-n, was determined by HPLC analysis, performed exploiting a Merck Hitachi D-7000 liquid chromatograph (UV detection at $242 \mathrm{~nm}$ ) and a Discovery C18 column ( $250 \mathrm{~mm} \times 4.6 \mathrm{~mm}, 5 \mu \mathrm{m}$, Supelco), with a gradient of $40 \%$ water and $60 \%$ acetonitrile and a flow rate of $1.5 \mathrm{~mL} / \mathrm{min}$. All the compounds showed percent purity values $\geq 95 \%$.

2-(4-Chlorophenoxy)acetonitrile, benzohydrazide, ethyl 3-(4-chlorophenyl)propanoate, 4chlorobenzene-1-carboximidamide hydrochloride, 4-aminothiophenol, 4-chlorobenzonitrile, 4bromobenzonitrile, 4-hydroxybenzonitrile, 2-[(4-chlorophenyl)sulfanyl]acetohydrazide and chloroethylacetate, used to obtain the target inhibitors, were from Alfa Aesar, Aldrich and Fluka. 
Synthesis of N'-(2-(4-chlorophenoxy)-1-aminoethylidene)benzohydrazide, 46. A solution of 2(4-chlorophenoxy)acetonitrile 44, (1.00 mmol), and sodium ethoxide $(0.10 \mathrm{mmol})$ in absolute EtOH $(20 \mathrm{~mL})$ was left under stirring at room temperature for 1 hour, than benzohydrazide 45 , (1.00 mmol), was added and the resulting mixture was refluxed under stirring until the disappearance of the starting materials (TLC analysis). After cooling to room temperature, the solid precipitated was collected by filtration and purified by crystallization from EtOH. M.p. $195{ }^{\circ} \mathrm{C}$. Yield: $25 \% .{ }^{1} \mathrm{H}-\mathrm{NMR}(\delta$, ppm): 9.88 (s, 1H, exc.), 7.80 (d, 2H, J=7.8 Hz), 7.44 (d, 3H, J=7.3 Hz), 7.33 (d, 2H, J=8.8 Hz), 7.04 (d, 2H, $\mathrm{J}=8.9 \mathrm{~Hz}), 6.56$ (s, 2H, exc.), $4.52(\mathrm{~s}, 2 \mathrm{H})$.

Synthesis of 3-((4-chlorophenoxy)methyl)-5-phenyl-1H-1,2,4-triazole, 43a. A suspension of N'(2-(4-chlorophenoxy)-1-aminoethylidene)benzohydrazide 46, $(1.00 \mathrm{mmol})$ in $\mathrm{POCl}_{3}(5 \mathrm{~mL})$ was heated under stirring at $\mathrm{T}=130{ }^{\circ} \mathrm{C}$ until the disappearance of the starting material (TLC analysis). Once the reaction was complete, the resulting mixture was carefully poured into crushed ice and the separated solid was collected by filtration and purified by crystallization from EtOH. M.p. 154-155 ${ }^{\circ} \mathrm{C}$. Yield: $33 \% .{ }^{1} \mathrm{H}-\mathrm{NMR}(\delta, \mathrm{ppm}):$ 8.01-7.97 (m, 2H), $7.47(\mathrm{~s}, 3 \mathrm{H})$, 7.37-7.32 (m, 2H), 7.11-7.07 $(\mathrm{m}, 2 \mathrm{H}), 5.20(\mathrm{~s}, 2 \mathrm{H}) .{ }^{13} \mathrm{C}-\mathrm{NMR}(\delta, \mathrm{ppm}): 159.65,157.15,146.28,132.43,131.92,131.12,129.41$, 129.20, 127.54, 126.74, 117.50, 60.34. HRMS (ESI) $[\mathrm{M}+\mathrm{H}]^{+}$calculated for $\mathrm{C}_{15} \mathrm{H}_{12} \mathrm{ClN}_{3} \mathrm{O}: 286.0669$, found: 286.0607 .

Synthesis of 3-(4-chlorophenyl)propanehydrazide, 48 [34]. The commercially available ethyl 3(4-chlorophenyl)propanoate $47(1.00 \mathrm{mmol})$ was allowed to react with hydrazine $(3.00 \mathrm{mmol})$ in $\mathrm{MeOH}$ solution $(10 \mathrm{~mL})$, at reflux, until the disappearance of the starting material (TLC analysis). The solvent was removed in vacuo and the solid obtained was purified by crystallization from EtOH. M.p. $121-122{ }^{\circ} \mathrm{C}$. Yield: $89 \% .{ }^{1} \mathrm{H}-\mathrm{NMR}(\delta, \mathrm{ppm}): 8.30$ (s, 1H, exc.), 7.30-7.16 (m, 6H), 2.76 (t, 2H, $\mathrm{J}=8.0 \mathrm{~Hz}), 2.27(\mathrm{t}, 2 \mathrm{H}, \mathrm{J}=8.0 \mathrm{~Hz}), 5.20(\mathrm{~s}, 2 \mathrm{H})$.

Synthesis of 3-(4-chlorophenethyl)-5-(4-chlorophenyl)-1H-1,2,4-triazole, 43b. A solution of 3-(4chlorophenyl)propanehydrazide 48, $(1.00 \mathrm{mmol})$, and sodium ethoxide $(2.00 \mathrm{mmol})$ in absolute EtOH $(20 \mathrm{~mL})$ was left under stirring at room temperature for 1 hour. The commercially available 4- 
chlorobenzene-1-carboximidamide hydrochloride 46 (1.00 mmol) was then added and the resulting mixture was refluxed until the disappearance of the starting materials (TLC analysis). The solvent was removed in vacuo and the solid obtained was purified by crystallization from toluene. M.p. 116$118^{\circ} \mathrm{C}$. Yield: $30 \% .{ }^{1} \mathrm{H}-\mathrm{NMR}(\delta, \mathrm{ppm}): 8.03$ (bs, $1 \mathrm{H}$, exc.), $7.80(\mathrm{~d}, 2 \mathrm{H}, \mathrm{J}=6.6 \mathrm{~Hz}), 7.52(\mathrm{~d}, 2 \mathrm{H}, \mathrm{J}=6.8$ $\mathrm{Hz}), 7.33-7.19(\mathrm{~m}, 4 \mathrm{H}), 2.82(\mathrm{t}, 2 \mathrm{H}, \mathrm{J}=7.8 \mathrm{~Hz}), 2.36(\mathrm{t}, 2 \mathrm{H}, \mathrm{J}=7.8 \mathrm{~Hz}) .{ }^{13} \mathrm{C}-\mathrm{NMR}(\delta, \mathrm{ppm}): 173.65$, $167.25,140.61,136.54,133.50,130.97,130.88,130,63,129.28,128.76,128.59,36,86,30.54$. HRMS (ESI) $[\mathrm{M}+\mathrm{H}]^{+}$calculated for $\mathrm{C}_{16} \mathrm{H}_{14} \mathrm{Cl}_{2} \mathrm{~N}_{3}: 317.0487$, found: 318.0408 .

General synthesis of 3,5-disubstituted-1,2,4-triazoles, 5, 43d-i and 55a,b. A mixture of 2-((4chlorophenyl)thio)acetohydrazide $\mathbf{5 0}(1.00 \mathrm{mmol})$, the suitably substituted nitrile $(3.00 \mathrm{mmol})$, and $\mathrm{K}_{2} \mathrm{CO}_{3}(0.5 \mathrm{mmol})$ in $n$ - $\mathrm{BuOH}(2 \mathrm{~mL})$ was stirred for $16 \mathrm{~h}$ in a reusable sealed tube at $150{ }^{\circ} \mathrm{C}$, in an oil bath. The progress of the reaction was monitored by the disappearance of the hydrazide by TLC analysis. The solvent was removed in vacuo and the residue obtained was purified by flash chromatography (hexanes/EtOAc 1:1).

5-(4-Chlorophenyl)-3-(((4-chlorophenyl)thio)methyl)-1H-1,2,4-triazole, 5. White solid. M.p. 121-122 ${ }^{\circ}$ C. Yield: 51\%. ${ }^{1} \mathrm{H}-\mathrm{NMR}$ ( $\delta$, ppm): 10.63 (bs, 1H, exc.), 7.93 (d, 2H, J=8.4 Hz), 7.42 (d, $2 \mathrm{H}, \mathrm{J}=8.0 \mathrm{~Hz}), 7.31-7.25(\mathrm{~m}, 4 \mathrm{H}), 4.27(\mathrm{~s}, 2 \mathrm{H}) .{ }^{13} \mathrm{C}-\mathrm{NMR}(\delta, \mathrm{ppm}): 159.52,156.95,136.28,133.43$, 132.72, 131.22, 129.41, 129.13, 128.54, 127.74, 127.49, 30.34. HRMS (ESI) $[\mathrm{M}+\mathrm{H}]^{+}$calculated for $\mathrm{C}_{15} \mathrm{H}_{11} \mathrm{Cl}_{2} \mathrm{~N}_{3} \mathrm{~S}$ : 335.0051 , found: 335.0233 .

5-(4-Bromophenyl)-3-(((4-chlorophenyl)thio)methyl)-1H-1,2,4-triazole, 43d. White solid. M.p. 156-158 ${ }^{\circ} \mathrm{C}$. Yield: $33 \% .{ }^{1} \mathrm{H}-\mathrm{NMR}(\delta, \mathrm{ppm}): 7.84$ (d, 2H, J=8.0 Hz), 7.53 (d, 2H, J=8.4 Hz), 7.26$7.19(\mathrm{~m}, 4 \mathrm{H}), 4.27$ (s, 2H). ${ }^{13} \mathrm{C}-\mathrm{NMR}(\delta, \mathrm{ppm}): 159.32,157.65,135.88,132.93,132.43,131.62$, 129.27, 129.06, 128.82, 127.78, 127.49, 29.34. HRMS (ESI) $[\mathrm{M}+\mathrm{H}]^{+}$calculated for $\mathrm{C}_{15} \mathrm{H}_{11} \mathrm{BrClN}_{3} \mathrm{~S}$ : 378.9546, found: 378.9681 .

4-(3-(((4-Chlorophenyl)thio)methyl)-1H-1,2,4-triazol-5-yl)phenol, 43e. White solid. M.p. 139$141{ }^{\circ} \mathrm{C}$. Yield: $21 \% .{ }^{1} \mathrm{H}-\mathrm{NMR}(\delta, \mathrm{ppm}): 7.78(\mathrm{~d}, 2 \mathrm{H}, \mathrm{J}=8.4 \mathrm{~Hz}), 7.40-7.28(\mathrm{~m}, 4 \mathrm{H}), 7.01(\mathrm{~d}, 2 \mathrm{H}, \mathrm{J}=8.8$ $\mathrm{Hz}), 5.08$ (s, 2H). ${ }^{13} \mathrm{C}-\mathrm{NMR}(\delta, \mathrm{ppm}): 159.19,158.13,157.05,134.38,132.96,131.08,128.71$, 
125.13, 118.01, 34.21. HRMS (ESI) $[\mathrm{M}+\mathrm{H}]^{+}$calculated for $\mathrm{C}_{15} \mathrm{H}_{11} \mathrm{ClN}_{3} \mathrm{OS}$ : 317.0390, found: 317.0712 .

5-(4-(Benzyloxy)phenyl)-3-((4-chlorophenyl)thio)methyl)-1H-1,2,4-triazole, 43f. White solid. M.p. $161-162{ }^{\circ} \mathrm{C}$. Yield: $63 \% .{ }^{1} \mathrm{H}-\mathrm{NMR}(\delta, \mathrm{ppm}): 7.88$ (d, 2H, J=8.4 Hz), 7.41-7.22 (m, 9H), 7.04 (d, $2 \mathrm{H}, \mathrm{J}=86.8 \mathrm{~Hz}), 5.11(\mathrm{~s}, 2 \mathrm{H}), 4.24(\mathrm{~s}, 2 \mathrm{H}) .{ }^{13} \mathrm{C}-\mathrm{NMR}(\delta, \mathrm{ppm}): 158.98,158.15,157.09,136.47$, 134.38, 132.51, 131.33, 129.78, 128.97, 127.85, 127.01, 125.09, 116.12, 69.78, 34.45. HRMS (ESI) $[\mathrm{M}+\mathrm{H}]^{+}$calculated for $\mathrm{C}_{22} \mathrm{H}_{18} \mathrm{ClN}_{3} \mathrm{OS}: 407.0859$, found: 407.0903 .

4-(4-(3-(((4-Chlorophenyl)thio)methyl)-1H-1,2,4-triazol-5-yl)phenoxy)pyridine, 43g. Colorless solid. M.p. $157-157{ }^{\circ} \mathrm{C}$. Yield: $38 \% .{ }^{1} \mathrm{H}-\mathrm{NMR}(\delta, \mathrm{ppm}):$ 8.18-8.13 (m, 4H), $7.65(\mathrm{~d}, 2 \mathrm{H}, \mathrm{J}=8.4 \mathrm{~Hz})$, $7.38(\mathrm{~d}, 2 \mathrm{H}, \mathrm{J}=8.4 \mathrm{~Hz}), 7.29(\mathrm{~d}, 2 \mathrm{H}, \mathrm{J}=8.4 \mathrm{~Hz}), 6.58(\mathrm{~d}, 2 \mathrm{H}, \mathrm{J}=7.2 \mathrm{~Hz}), 4.59(\mathrm{~s}, 2 \mathrm{H}) .{ }^{13} \mathrm{C}-\mathrm{NMR}(\delta$, ppm): 162.81, 159.24, 158.67, 156.99, 163.28, 134.43, 132.31, 131.37, 130.41, 129.28, 128.63, 121.74, 103.49, 31.87. HRMS (ESI) $[\mathrm{M}+\mathrm{H}]^{+}$calculated for $\mathrm{C}_{20} \mathrm{H}_{15} \mathrm{ClN}_{4} \mathrm{OS}$ : 394.0655, found: 394.0787.

4-(3-(((4-Chlorophenyl)thio)methyl)-1H-1,2,4-triazol-5-yl)aniline, 43h. Yellow solid. M.p. 145$147{ }^{\circ} \mathrm{C}$. Yield: $49 \% .{ }^{1} \mathrm{H}-\mathrm{NMR}(\delta, \mathrm{ppm}): 7.69$ (d, 2H, J=8.4 Hz), 7.31-7.19 (m, 4H), 6.68 (d, 2H, J=8.4 $\mathrm{Hz}), 4.20$ (s, 2H). ${ }^{13} \mathrm{C}-\mathrm{NMR}(\delta, \mathrm{ppm}): 150.69,149.79,133.80,129.57,126.73,120.35,114.45$, 112.95, 99.76, 30.34. HRMS (ESI) $[\mathrm{M}+\mathrm{H}]^{+}$calculated for $\mathrm{C}_{15} \mathrm{H}_{13} \mathrm{ClN}_{4} \mathrm{~S}: 316.0549$, found: 316.0557 . 1-(4-(3-((4-Chlorophenyl)thio)methyl)-1H-1,2,4-triazol-5-yl)phenyl)-4-methylpiperazine, 43 . White solid. M.p. $172-174{ }^{\circ} \mathrm{C}$. Yield: $67 \% .{ }^{1} \mathrm{H}-\mathrm{NMR}(\delta, \mathrm{ppm}): 7.82(\mathrm{~d}, 2 \mathrm{H}, \mathrm{J}=8.4 \mathrm{~Hz}), 7.33-7.18$ (m, $4 \mathrm{H}), 6.88(\mathrm{~d}, 2 \mathrm{H}, \mathrm{J}=8.4 \mathrm{~Hz}), 4.22(\mathrm{~s}, 2 \mathrm{H}), 3.32-3.29(\mathrm{~m}, 4 \mathrm{H}), 2.71-2.69(\mathrm{~s}, 4 \mathrm{H}), 2.43$ (s, 3H). ${ }^{13} \mathrm{C}-$ NMR ( $\delta, \mathrm{ppm}): 158.93,158.14,151.98,133.90,132.71,131.03,129.62,129.11,127.59,125.70$, 118.98, 117.86, 115.42, 101.42, 54.47, 47.56, 45.48, 30.94. HRMS (ESI) $[\mathrm{M}+\mathrm{H}]^{+}$calculated for $\mathrm{C}_{20} \mathrm{H}_{22} \mathrm{ClN}_{5} \mathrm{~S}: 399.1284$, found: 399.1343.

4-(((5-phenyl-1H-1,2,4-triazol-3-yl)methyl)thio)aniline, 55a. Colorless oil. Yield: $52 \% .{ }^{1} \mathrm{H}-\mathrm{NMR}$ ( $\delta$, ppm): 14.01 (s, 1H, exc.), $7.96(\mathrm{~d}, 2 \mathrm{H}, \mathrm{J}=8.6 \mathrm{~Hz}), 7.41-7.48(\mathrm{~m}, 3 \mathrm{H}), 7.08(\mathrm{~d}, 2 \mathrm{H}, \mathrm{J}=8.5), 6.50(\mathrm{~d}$, $2 \mathrm{H}, \mathrm{J}=8.4 \mathrm{~Hz}), 5.26$ (s, 2H, exc.), 4.03 (s, 2H). ${ }^{13} \mathrm{C}-\mathrm{NMR}$ ( $\left.\delta, \mathrm{ppm}\right): 169,80,142,52,139.90,132.75$, 
$132,15,131.13,129,90,128.62,127.41,116.98,117.86,115.42,36.24$. HRMS (ESI) $[\mathrm{M}+\mathrm{H}]^{+}$ calculated for $\mathrm{C}_{15} \mathrm{H}_{15} \mathrm{~N}_{4} \mathrm{~S}: 283,0939$, found: 283.0999.

4-(((5-(4-Chlorophenyl)-1H-1,2,4-triazol-3-yl)methyl)thio)aniline, 55b. White solid. M.p. 168$170{ }^{\circ} \mathrm{C}$. Yield: $72 \% .{ }^{1} \mathrm{H}-\mathrm{NMR}$ ( $\left.\delta, \mathrm{ppm}\right): 14.03$ (s, 1H, exc.), 7.96 (d, 2H, J=8.6 Hz), 7.54 (d, 2H, $\mathrm{J}=8.5), 7.07(\mathrm{~d}, 2 \mathrm{H}, \mathrm{J}=8.4 \mathrm{~Hz}), 6.47(\mathrm{~d}, 2 \mathrm{H}, \mathrm{J}=8.5), 5.30\left(\mathrm{~s}, 2 \mathrm{H}\right.$, exc.), $4.04(\mathrm{~s}, 2 \mathrm{H}) .{ }^{13} \mathrm{C}-\mathrm{NMR}(\delta$, ppm): $169,80,142,52,139.90,132.75,132,15,131.13,129,90,128.62,127.41,116.98,117.86$, 115.42, 36.24. HRMS (ESI) $[\mathrm{M}+\mathrm{H}]^{+}$calculated for $\mathrm{C}_{15} \mathrm{H}_{14} \mathrm{ClN}_{4} \mathrm{~S}: 317,0549$, found: 317.0576 .

Synthesis of 5-(4-chlorophenyl)-3-(((4-chlorophenyl)sulfonyl)methyl)-1H-1,2,4-triazole, 43c. A solution of $5(1.00 \mathrm{mmol})$ in DCM $(10 \mathrm{~mL})$ was treated with $\mathrm{m}$-chloroperbenzoic acid $(3.00 \mathrm{mmol})$ and stirred at room temperature for $5 \mathrm{~h}$. The solid formed was removed by filtration and the filtrate was washed with sodium-bicarbonate solution, water and brine. The organic layer was dried over $\mathrm{Na}_{2} \mathrm{SO}_{4}$ and evaporated under vacuum. The residue obtained was purified by Flash Chromatography (hexanes/EtOAc 1:1). Yellow solid. M.p. $163-165{ }^{\circ} \mathrm{C}$. Yield: $81 \% .{ }^{1} \mathrm{H}-\mathrm{NMR}(\delta$, ppm): 7.82 (d, 2H, $\mathrm{J}=8.4 \mathrm{~Hz}), 7.73(\mathrm{~d}, 2 \mathrm{H}, \mathrm{J}=7.2 \mathrm{~Hz}), 7.49(\mathrm{~d}, 2 \mathrm{H}, \mathrm{J}=8.4 \mathrm{~Hz}), 7.43(\mathrm{~d}, 2 \mathrm{H}, \mathrm{J}=6.6 \mathrm{~Hz}), 4.66(\mathrm{~s}, 2 \mathrm{H}) .{ }^{13} \mathrm{C}-$ NMR $(\delta, \mathrm{ppm}): 158.31,156.03,135.17,129.98,129.71,129.28,127.66,127.08,125.87,124.62$, 29.70. HRMS (ESI) $[\mathrm{M}+\mathrm{H}]^{+}$calculated for $\mathrm{C}_{15} \mathrm{H}_{11} \mathrm{Cl}_{2} \mathrm{~N}_{3} \mathrm{O}_{2} \mathrm{~S}: 366.9949$, found: 366.9957 .

Synthesis of 2-((4-aminophenyl)thio)acetohydrazide, 54. A solution of 4-aminobenzenethiol (1.00 mmol), chloroethylacetate $(1.00 \mathrm{mmol})$, and $\mathrm{K}_{2} \mathrm{CO}_{3}(1.00 \mathrm{mmol})$ in DMF $(5 \mathrm{~mL})$ was left under stirring at room temperature until the disappearance of the starting material (TLC analysis). Once the reaction was complete, the solvent was removed in vacuo and the resulting residue was washed with water to obtain the key intermediate ethyl 2-((4-aminophenyl)thio)acetate. This latter was then allowed to react with hydrazine $(3.00 \mathrm{mmol})$ in $\mathrm{MeOH}$ solution $(10 \mathrm{~mL})$, at reflux, until the disappearance of the starting material (TLC analysis). The solvent was removed in vacuo and the solid obtained was purified by crystallization from EtOH. M.p. $94-96{ }^{\circ} \mathrm{C}$. Yield: $90 \% .{ }^{1} \mathrm{H}-\mathrm{NMR}(\delta$, ppm): 9.03 (s, 1H, exc.), 7.11 (d, 2H, J=8.5), 6.51 (d, 6H, J=8.5), 5.24 (s, 2H, exc.), 3.33 (s, 2H, exc.), $3.30(\mathrm{~s}, 2 \mathrm{H})$. 


\section{General synthesis of 1-(4-(((5-(4-chlorophenyl)-1H-1,2,4-triazol-3-yl)methyl)thio)phenyl)-3-}

(substituted)phenylurea, $\mathbf{4 3 j}$-l. A solution of the 1,2,4-triazole derivative $\mathbf{5 5}(1.00 \mathrm{mmol})$ and the appropriate phenyl isocyanate $(1.00 \mathrm{mmol})$ in THF $(20 \mathrm{~mL})$ was left under stirring at room temperature until the disappearance of the starting material (TLC analysis). Once the reaction was complete, the solvent was removed in vacuo and the residue obtained was purified by crystallization from the suitable solvent.

1-(4-(((5-(4-Chlorophenyl)-1H-1,2,4-triazol-3-yl)methyl)thio)phenyl)-3-phenylurea, 43j. White solid. M.p. $186-189{ }^{\circ}$ C. Cryst. solvent: MeOH. Yield: $24 \% .{ }^{1} \mathrm{H}-\mathrm{NMR}(\delta, \mathrm{ppm}): 14.10$ (s, $1 \mathrm{H}$, exc.), 8.80 (s, 1H, exc.), 8.75 (s, 1H, exc), 7.97 (dd, 2H, J=8.6 Hz, J=4.8 Hz), 7.54 (d, 2H, J=8.6 Hz), 7.45$7.41(\mathrm{~m}, 4 \mathrm{H}), 7.34(\mathrm{dd}, 2 \mathrm{H}, \mathrm{J}=8.7 \mathrm{~Hz}, \mathrm{~J}=4.7 \mathrm{~Hz}), 7.28$ (t, 2H, J=7.7), 6.97 (t, 1H, J=7.3 Hz), 4.23 (s, 2H). ${ }^{13} \mathrm{C}-\mathrm{NMR}(\delta, \mathrm{ppm}): 156,50,152,88,140,06,139,48,134,29,131,31,129,39,129,24,129,07$, $127,98,126,97,122,35,119,17,118,69,30,63$. HRMS (ESI) $[\mathrm{M}+\mathrm{H}]^{+}$calculated for $\mathrm{C}_{22} \mathrm{H}_{19} \mathrm{ClN}_{5} \mathrm{OS}$ : 436.0921, found: 436,0999.

\section{1-(3-acetylphenyl)-3-(4-(((5-(4-chlorophenyl)-1H-1,2,4-triazol-3-yl)methyl)thio)phenyl)urea,}

43k. White solid. M.p. $158-160^{\circ}$ C. Yield: $25 \% .{ }^{1} \mathrm{H}-\mathrm{NMR}(\delta, \mathrm{ppm}): 14.10$ (s, 1H, exc.), 8.97 (s, 1H, exc.), 8.79 (s, 1H, exc), 8.06 (t, 1H, J=1.9), 7.97 (dd, 2H, J=8.6 Hz, J=1.5 Hz), 7.67 (d, 1H, J=8.0 $\mathrm{Hz}), 7.61-7.58(\mathrm{~m}, 2 \mathrm{H}), 7.48-7.41(\mathrm{~m}, 4 \mathrm{H}), 7.26(\mathrm{~d}, 2 \mathrm{H}, \mathrm{J}=2.0 \mathrm{~Hz}), 4.10(\mathrm{~s}, 2 \mathrm{H}), 2.69(\mathrm{~s}, 3 \mathrm{H}) .{ }^{13} \mathrm{C}-$ NMR $(\delta, \mathrm{ppm}): 161,15,152,91,140,48,137,84,130,67,129,80,129,65,129,56,129,34,129,11$, $126,48,126,18,123,33,122,49,121,91,118,63,117,86,117,02,116,42,27,26$. HRMS (ESI) [M + $\mathrm{H}]^{+}$calculated for $\mathrm{C}_{24} \mathrm{H}_{22} \mathrm{~N}_{5} \mathrm{O}_{2} \mathrm{~S}: 444.1416$, found: 444,1494 .

\section{1-(4-(((5-(4-chlorophenyl)-1H-1,2,4-triazol-3-yl)methyl)thio)phenyl)-3-(2,5-dimethoxyphenyl)}

urea, 43l. White solid. M.p. $178-180{ }^{\circ} \mathrm{C}$. Cryst. solvent: MeOH. Yield: $25 \% .{ }^{1} \mathrm{H}-\mathrm{NMR}$ ( $\delta$, ppm): 14.13 (s, 1H, exc.), 9.42 (s, 1H, exc.), 8.26 (s, 1H, exc.), 7.97 (dd, 2H, J=8.6, J=2.4), 7.84 (d, 1H, $\mathrm{J}=3.0), 7.55(\mathrm{~d}, 2 \mathrm{H}, \mathrm{J}=8.4), 7.42(\mathrm{~d}, 2 \mathrm{H}, \mathrm{J}=8.7), 7.35$ (d, 2H, J=8.7), 6.92 (d, 1H, J=8.8), 6.49 (dd, 1H, $\mathrm{J}=8.4, \mathrm{~J}=3.0), 4.23$ (s, 2H), 3.82 (s, 3H), 3.69 (s, 3H). ${ }^{13} \mathrm{C}-\mathrm{NMR}(\delta, \mathrm{ppm}): 153,74,152,63,131,96$, $129,85,129,62,129,42,129,14,128,00,126,48,126,18,123,33,122,49,121,91,118,63,117,86$, 
117,02, 116,42, 63,95, 56,79, 29,35. HRMS (ESI) $[\mathrm{M}-\mathrm{H}]^{-}$calculated for $\mathrm{C}_{24} \mathrm{H}_{21} \mathrm{ClN}_{5} \mathrm{O}_{3} \mathrm{~S}: 494.1132$, found: 494,1054.

Synthesis of 4-chloro-N-(4-(((5-(4-chlorophenyl)-1H-1,2,4-triazol-3-yl)methyl)thio)phenyl) benzamide, 43m. A solution of the 1,2,4-triazole derivative 55 (1.00 mmol) and 4-chlorobenzoyl chloride $(1.20 \mathrm{mmol})$ in toluene $(20 \mathrm{~mL})$ was left under stirring at room temperature until the disappearance of the starting material (TLC analysis). Once the reaction was complete, the solvent was removed in vacuo and the residue obtained was washed with water and purified by recrystallization from $\mathrm{MeOH}$. M.p. $228-230{ }^{\circ} \mathrm{C}$. Yield: $46 \% .{ }^{1} \mathrm{H}-\mathrm{NMR}(\delta, \mathrm{ppm}): 14.12$ (s, $1 \mathrm{H}$, exc.), 10.35 (s, 1H, exc.), 7.97 (dd, 4H, J=10.2, J=4.5), 7.73 (d, 2H, J=8.7), 7.62-7.60 (m, 2H), 7.56-7.54 (m, 2H), $7.42(\mathrm{~d}, 2 \mathrm{H}, \mathrm{J}=8.7), 4.31(\mathrm{~s}, 2 \mathrm{H}) .{ }^{13} \mathrm{C}-\mathrm{NMR}(\delta, \mathrm{ppm}): 164,87,136,93,133,94,130,09$, 129,94, 128,95, 128,00, 121,32, 27,26. HRMS (ESI) $[\mathrm{M}-\mathrm{H}]^{-}$calculated for $\mathrm{C}_{22} \mathrm{H}_{15} \mathrm{Cl}_{2} \mathrm{~N}_{4} \mathrm{OS}$ : 453.0422, found: 453,0344.

Synthesis of N-(4-(((5-(4-chlorophenyl)-1H-1,2,4-triazol-3-yl)methyl)thio)phenyl)benzene sulfonamide, $\mathbf{4 3 n}$. A solution of the 1,2,4-triazole derivative $\mathbf{5 5}$ (1.00 mmol), benzenesulfonyl chloride $(1.20 \mathrm{mmol})$ and and triethyl amine $(1.20 \mathrm{mmol})$ in toluene $(20 \mathrm{~mL})$ was left under stirring at room temperature until the disappearance of the starting material (TLC analysis). Once the reaction was complete, the solvent was removed in vacuo and the residue obtained was purified by recrystallization from EtOH. M.p. $228-230{ }^{\circ} \mathrm{C}$. Yield: 46\%. ${ }^{1} \mathrm{H}-\mathrm{NMR}(\delta, \mathrm{ppm}): 14,10(\mathrm{~s}, 1 \mathrm{H}$, exc.), 10,35 (s, 1H, exc.), 7.95 (d, 2H, J=8.7), 7.73 (d, 2H, J=7.6), 7.59-7.51 (m, 5H), 7.28 (d, 2H, J=8.7), 7.02 (d, 2H, J=8.7), 4.48 (s, 2H). ${ }^{13} \mathrm{C}-\mathrm{NMR}(\delta, \mathrm{ppm}): 164,87,136,93,133,94,130,09,129,94,128,95$, 128,00, 121,32, 27,26. HRMS (ESI) $[\mathrm{M}+\mathrm{H}]^{+}$calculated for $\mathrm{C}_{21} \mathrm{H}_{17} \mathrm{ClN}_{4} \mathrm{O}_{2} \mathrm{~S}_{2}$ : 457.0481, found: 457,0404 .

Synthesis of 5-(4-chlorophenyl)-3-((4-chlorophenylthio)methyl)-1H-1,2,4-triazole potassium salt, 42. Anhydrous ethyl ether was added dropwise to an ice-cooled, stirred solution of 5-(4chlorophenyl)-3-((4-chlorophenylthio)methyl)-1H-1,2,4-triazole $\quad 5 \quad(1.00 \quad \mathrm{mmol}) \quad$ in $\quad 0.10 \quad \mathrm{M}$ 
$\mathrm{KOH} / \mathrm{EtOH}(10 \mathrm{~mL})$. The resulting solid was collected by filtration. M.p.: $>300{ }^{\circ} \mathrm{C}$. Yield: $95 \% .{ }^{1} \mathrm{H}-$ $\operatorname{NMR}(\delta, p p m): 7.90$ (d, 2H, J=8.60 Hz), $7.46(\mathrm{~d}, 2 \mathrm{H}, \mathrm{J}=8.60 \mathrm{~Hz}), 7.33(\mathrm{~s}, 4 \mathrm{H}), 4.18(\mathrm{~s}, 2 \mathrm{H})$.

Biology. Tyrosine Kinase Assays. Compounds selected by VS were purchased from Maybridge, and subjected to NMR analysis prior to testing for their inhibitory activity, to verify their correspondence to the chemical structures shown in Tables 2 and SI2. In addition, HPLC analyses were performed, to verify their consistence with a purity of at least $95 \%$. Analyses were performed using a Merck Hitachi D-7000 liquid chromatograph (UV detection at $242 \mathrm{~nm}$ ) and a Discovery C18 column (250 $\mathrm{mm} \times 4.6 \mathrm{~mm}, 5 \mu \mathrm{m}$, Supelco), with a gradient of water and acetonitrile, suitably fitted to each compound, and a flow rate of $1.4 \mathrm{~mL} / \mathrm{min}$. All the compounds showed percent purity values $\geq 95 \%$. The reference standard, vandetanib, was from Sequoia Research Products Ltd. Human recombinant protein tyrosine kinases RET, RET ${ }^{\mathrm{V} 804 \mathrm{~L}}$, VEGFR2 and EGFR, and Protein tyrosine kinase assay kit, Omnia $^{\mathrm{TM}}$ Tyr Human Recombinant Kit 7, were from Invitrogen.

Tyrosine kinases inhibitory assays. They were performed in 96-well microtiter plates using the Omnia $^{\mathrm{TM}}$ Tyr Human Recombinant Kit 7 , in accordance with the manufacturer's protocol and following a previously reported procedures [23-25]. Briefly, the kinase activity of each protein was determined fluorimetrically by monitoring the increase in fluorescence resulting from phosphorylation of a peptide substrate, catalyzed by the enzyme in the presence of ATP. The target kinase was assayed at $30{ }^{\circ} \mathrm{C}$ in a reaction mixture containing Tyrosine Kinase Reaction Buffer, Tyrosine Kinase Substrate, ATP; $5 \mu \mathrm{L}$ of $1 \mathrm{mM}$ DTT; $25 \mu \mathrm{L}$ of ultrapure water and $5 \mu \mathrm{L}$ of $3 \mathrm{mU} / \mathrm{mL}$ protein kinase in a total volume of $50 \mu \mathrm{L}$. All the above reagents, except the protein, were incubated at $30{ }^{\circ} \mathrm{C}$ for $5 \mathrm{~min}$. The target protein kinase was then added to start the reaction, which was monitored with the fluorescence meter Victor $3{ }^{\mathrm{TM}}$ PerkinElmer at $360 \mathrm{~nm}$ (excitation filter) and $485 \mathrm{~nm}$ (emission filter). Kinase activity was calculated from a linear least-squares fit of the data for fluorescence intensity versus time.

The inhibitory activity of the test compounds was assayed by adding $5 \mu \mathrm{L}$ of the inhibitor solution to the reaction mixture described above. All the products were dissolved in 100\% DMSO and diluted to 
the appropriate concentrations with Tyrosine Kinase Reaction Buffer, provided by the kit. The final concentration of DMSO in assay solutions never exceeded $1 \%$, and proved to have no effects on protein activity. The inhibitory effect of the products was routinely estimated at a concentration of $10^{-4} \mathrm{M}$. Those compounds found to be active were then tested at additional concentrations between $10^{-5}$ and $10^{-8} \mathrm{M}$. For a proper comparison, vandetanib was employed as the reference standards. The determination of the $\mathrm{IC}_{50}$ values was performed by linear regression analysis of the log-dose response curves, which were generated using at least five concentrations of the inhibitor causing an inhibition between $20 \%$ and $80 \%$, with three replicates at each concentration. (Tables 2 and SI2). To exclude any possible nonspecific/promiscuous inhibition of the target kinases, all the assays pertaining the active compounds were repeated in the presence of $0.01 \%$ Triton X-100, as suggested by Shoichet et al. [35]. None of the observed inhibitory activities was affected by the addition of the nonionic detergent, thus avoiding any risk of false positive results.

Cell viability and proliferation assays on TT cell line. Thyroid medullary carcinoma derived cell line TT was from Interlab Cell Line Collection, Genova, Italy. Cells were cultured in medium Ham's F12 containing $10 \%$ FBS, $2 \mathrm{mM} \mathrm{L-glutamine}$ at $37^{\circ} \mathrm{C}$ in $5 \% \mathrm{CO}_{2}$ humidified atmosphere [36].

Cell cultures and treatment with compound 5. TT cell cultures were treated (48 h) with 5, 30 and $50 \mu \mathrm{M}$ compound $\mathbf{5}$, or with vehicle alone. All experiments were repeated three times. The number of viable cells was evaluated by a viability and proliferation assay (Cell Proliferation Reagent WST1; Roche). Briefly, the tetrazolium salts, added to the culture medium, are cleaved to formazan by cellular enzymes. An expansion in the number of viable cells causes an increase in the overall activity of mitochondrial dehydrogenases in the sample, which is linked to an increase in the amount of formazan dye formed, which correlates to the number of metabolically active cells. The formazan dye produced was quantified by measuring the absorbance of the dye solution at $450 \mathrm{~nm}$ with a scanning multiwell spectrophotometer (ELISA reader) [37]. Cells were seeded in a 96 wells microtiter plate at a concentration of 35000 cells $/ \mathrm{ml}$ in a final volume of $100 \mu \mathrm{l}$ in each well. Then, they were incubated for $48 \mathrm{~h}$ with the above mentioned concentrations of the test compound, $\mathbf{5}$, or 
with vehicle alone, in a humidified atmosphere $\left(37^{\circ} \mathrm{C}, 5 \% \mathrm{CO}_{2}\right)$. After the incubation period, $10 \mu \mathrm{l}$ of the Cell Proliferation Reagent WST-1 were added to $100 \mu \mathrm{l}$ of culture medium in each well and the absorbance of the samples was measured at $450 \mathrm{~nm}$ against the control (the same cells without any treatment) using a microtiter plate (ELISA) reader. The same volume of culture medium and Cell Proliferation Reagent WST-1 (10 $\mu$ l of Cell Proliferation Reagent WST-1/100 $\mu$ l of culture medium) was added into one well (absorbance of culture medium plus WST-1 in the absence of cells) as a blank position for the ELISA reader. The absorbance was measured again after 1 and $2 \mathrm{~h}$. The measured absorbance of blank was subtracted from control and treatments and the control was normalized to $100 \%$ for each assay; treatments were expressed as \% of the control (Figure 5) [38,39]. Data analysis. Values are given as mean \pm SD for normally distributed variables (in text), or mean \pm SEM (in Figures), otherwise as median and (interquartile range). The mean group values were compared by one-way ANOVA for normally distributed variables, otherwise by the Mann-Whitney $U$ or Kruskal-Wallis test. Proportions were compared by the $\chi^{2}$ test. Post hoc comparisons on normally distributed variables were carried out using the Bonferroni-Dunn test.

Cell viability and proliferation assays on thyroid tissue from patients. Surgical thyroid tissue was obtained from five patients with medullary thyroid cancer (MTC) at the time of surgery. The study subjects gave their informed consent to the study, which was approved by the local ethical committee. Cell cultures and treatment with compound 5. MTC cells were maintained in RPMI 1640 medium (Sigma-Aldrich Corp., St. Louis, MO, USA) supplemented with 16\% fetal bovine serum (FBS; Seromed, Biochrom, Berlin, Germany), $100 \mathrm{IU} / \mathrm{ml}$ penicillin, and $100 \mu \mathrm{g} / \mathrm{ml}$ streptomycin in a $37^{\circ} \mathrm{C}$ incubator with $5 \% \mathrm{CO}_{2}$ [40]. Cultures of MTC cells were treated (48 h) with 5, 10, 30 and $50 \mu \mathrm{M}$ compound $\mathbf{5}$ or with vehicle alone. All experiments were repeated three times with the different cell preparations. For quantitation of total protein in cell preparations, lysis and homogenization were performed and the sample was immediately assayed for its protein concentration by conventional methods [39]. 
The number of viable cells was evaluated by a viability and proliferation assay (Cell Proliferation Reagent WST-1; Roche). The tetrazolium salts, added to the culture medium, are cleaved to formazan by cellular enzymes. An expansion in the number of viable cells causes an increase in the overall activity of mitochondrial dehydrogenases in the sample, which is linked to an increase in the amount of formazan dye formed, which correlates to the number of metabolically active cells. The formazan dye produced was quantified by measuring the absorbance of the dye solution at $450 \mathrm{~nm}$ with a scanning multiwell spectrophotometer (ELISA reader).

Cells were seeded in a 96 wells microtiter plate at a concentration of 35000 cells $/ \mathrm{ml}$ in a final volume of $100 \mu \mathrm{l}$ in each well. Then, they were incubated for $48 \mathrm{~h}$ with the above mentioned concentrations of 5 or with vehicle alone, in a humidified atmosphere $\left(37^{\circ} \mathrm{C}, 5 \% \mathrm{CO}_{2}\right)$. After the incubation period, $10 \mu \mathrm{l}$ of the Cell Proliferation Reagent WST-1 were added to $100 \mu \mathrm{l}$ of culture medium in each well and the absorbance of the samples was measured at $450 \mathrm{~nm}$ against the control (the same cells without any treatment) using a microtiter plate (ELISA) reader. The same volume of culture medium and Cell Proliferation Reagent WST-1 (10 $\mu$ l of Cell Proliferation Reagent WST-1/100 $\mu$ l of culture medium) was added into one well (absorbance of culture medium plus WST-1 in the absence of cells) as a blank position for the ELISA reader.

The absorbance was measured again after 1 and $2 \mathrm{~h}$. The measured absorbance of blank was subtracted from control and treatments and the control was normalized to $100 \%$ for each assay; treatments were expressed as \% of the control (Figure 5) [38,41].

Data analysis. Values are given as mean \pm SD for normally distributed variables (in text), or mean \pm SEM (in Figures), otherwise as median and (interquartile range). Experiments were repeated three times with the cells from each donor. The mean of the experiments in the five specimens from different donors is reported. The mean group values were compared by one-way ANOVA for normally distributed variables, otherwise by the Mann-Whitney $U$ or Kruskal-Wallis test. Proportions were compared by the $\chi^{2}$ test. Post hoc comparisons on normally distributed variables were carried out using the Bonferroni-Dunn test. 
Virtual Screening. For our study, the Maybridge HitFinder DataBase of 14,400 compounds was selected. A filtering procedure was applied to provide a more focused library of compounds. Specifically, all scaffolds having a H-bond donor and H-bond acceptor within 3-7 bonds distance have been retained. The result from this filtering was a new subset of compounds containing 6,248 structures that were prepared using LigPrep [42] generating all possible tautomeric, enantiomeric, and protonation states and keeping only those possessing good ADME properties (calculated by means of QikProp).

As for the RET X-ray selection, a detailed comparison among the phosphorylated structures currently available was performed. A superposition on the $\alpha$ carbon atoms using 2IVV [29] as the reference indicated that the protein folding was highly preserved. Thus, the two structures with the highest resolutions, 2IVV and 2X2L [43], both co-crystallized with an organic inhibitor were taken into account. The superposition of 2IVV and 2X2L structures reveals that the K758 can assume different orientations, upon ligand binding. In fact, in 2X2L, the phenyl-methylidene-dihydroindolone inhibitor does not occupy the N-lobe hydrophobic cavity, and the K758 partially blocks the pocket entrance. Conversely, the PP1 inhibitor in 2IVV enters the small cavity with its methyl-phenyl moiety forcing the long K758 side chain to shift its orientation. Cross-docking experiments showed that 2IVV can allocate also larger inhibitors like vandetenib, while 2X2L does not. Thus, 2IVV was chosen for our Virtual Screening campaign and was prepared using Protein Preparation Wizard implemented in Maestro Suite 2011 [44]. During the preparation, all water molecules were deleted, hydrogen atoms added, the complex minimized. The receptor grid was generated using the grid generation in Glide 5.7 [45], centered around the crystallized ligand using default settings. For docking, the SP mode in Glide was used first, retaining only the best 1000 hits that were rescored in XP mode [46]. All settings were left at the default.

Supporting Information Available. Binding mode of the 2H-1,2,4-triazole tautomer of 5 in the RET binding site and its superposition with the 1H-1,2,4-triazole tautomer; Maybridge Codes and Docking 
Scores of the Top five hundreds Ranked Screened Compounds; Table including structures, Maybridge codes and inhibitory activities of test compounds 7-42; Supplementary Materials and Methods: CEREP In Vitro Pharmacology and Enzyme and Uptake Assays, Experimental conditions for early ADME characterization. Information about commercially available kinase-focused databases. Ancillary synthetic data.

\section{Author Contribution}

${ }^{\S}$ These authors equally contributed to this work. The manuscript was written through contributions of all authors. All authors have given approval to the final version of the manuscript.

\section{Abbreviations}

MTC, medullary thyroid carcinoma; RET, REarranged during Transfection; VEGFR, vascular endothelial growth factor receptor, EGFR, epidermal growth factor receptor; PDGFR, plateletderived growth factor receptor; ATP, adenosine triphosphate; VS, virtual screening.

\section{Acknowledgement}

C.L.M. acknowledges the University of Pisa for the financial support (PRA_2017_51 Project). The authors thanks Acceleras s.r.l. (Milan, Italy) for early ADME characterization of compound $\mathbf{5}$.

\section{References}

[1] Boufraqech, M.; Patel, D.; Xiong, Y.; Kebebew, E. Diagnosis of thyroid cancer: state of art. Expert Opin. Med. Diagn. 2013, 7, 331-342.

[2] Lewis, C. E.; Yeh, M. W. Inherited endocrinopathies: an update. Mol Genet Metab. 2008, 94 , 271-282.

[3] Vini, L.; Harmer, C. Management of thyroid cancer. Lancet Oncol. 2002, 3, 407-414.

[4] Giunti, S.; Antonelli, A.; Amorosi, A.; Santarpia, L. Cellular signaling pathway alterations and potential targeted therapies for medullary thyroid carcinoma. Int. J. Endocrinol. 2013, 803171.

[5] Sugawara, M.; Ly, T.; Hershman, J. M. Medullary thyroid cancer-current treatment strategy, novel therapies and perspectives for the future. Horm. Cancer. 2012, 3, 218-226. 
[6]Antonelli, A.; La Motta C. Novel therapeutic clues in thyroid carcinomas: the role of targeting cancer stem cells. Med. Res. Rev. 2017, 37, 1299-1317.

[7] Moore, S. W. Molecular targets in medullary thyroid carcinoma. Gene Ther. Mol. Biol. 2008, $12,181-188$.

[8] Phay, J. E.; Shah, M. H. Targeting RET receptor tyrosine kinase activation in cancer. Clin. Cancer Res. 2010, 16, 5936-5941.

[9] Borrello, M. G.; Ardini, E.; Locati, L. D.; Greco, A.; Licitra, L.; Pierotti, M. A RET inhibition: implications in cancer therapy. Expert Opin. Ther. Targets. 2013, 17, 403-419.

[10] Elisei, R.; Cosci, B.; Romei, C.; Bottici, V.; Ronzini, G.; Molinaro, E.; Agate, L.; Vivaldi, A.; Faviana, P.; Basolo, F.; Miccoli, P.; Berti, P.; Pacini, F.; Pinchera, A. Prognostic significance of somatic RET oncogene mutations in sporadic medullary thyroid cancer: a 10-year follow-up study. J. Clin. Endocrinol. Metab. 2008, 93, 682-687.

[11] Chau, N. G.; Haddad, R. I. Vandetanib for the treatment of medullary thyroid cancer Clin. Cancer Res. 2013, 19, 524-529.

[12] Elisei, R.; Schlumberger, M. J.; Müller, S. P.; Schöffski, P.; Brose, M. S.; Shah, M. H.; Licitra, L.; Jarzab, B.; Medvedev, V.; Kreissl, M. C.; Niederle, B.; Cohen, E. E.; Wirth, L. J.; Ali, H. Hessel, C.; Yaron, Y.; Ball, D.; Nelkin, B.; Sherman, S. I. Cabozantinib in progressive medullary thyroid cancer. J Clin Oncol. 2013, Sep 3.

[13] Tortora, G.; Ciardiello, F.; Gasparini, G. Combined targeting of EGFR-dependent and VEGFdependent pathways: rationale, preclinical studies and clinical applications. Nat. Clin. Pract. Oncol. 2008, 5, 521-530.

[14] Pao, W.; Miller, V. A. Epidermal growth factor receptor mutations, small-molecule kinase inhibitors, and non-small-cell lung cancer: current knowledge and future directions. J. Clin. Oncol. 2005, 23, 2556-2568. 
[15] Carlomagno, F.; Guida, T.; Anaganti, S.; Vecchio, G.; Fusco, A.; Ryan, A. J.; Billaud, M.; Santoro, M. Disease associated mutations at valine 804 in the RET receptor tyrosine kinase confer resistance to selective kinase inhibitors. Oncogene. 2004, 23, 6056-6063.

[16] Dixit, A.; Torkamani, A.; Schork, N. J.; Verkhivker, G. Computational modeling of structurally conserved cancer mutations in the RET and MET kinases: the impact on protein structure, dynamics, and stability. Biophys. J. 2009, 96, 858-874.

[17] Dubinina, G. G.; Chupryna, O. O.; Platonov, M. O.; Borisko, P. O.; Ostrovska, G. V.; Tolmachov, A. O.; Shtil, A. A. In silico design of protein kinase inhibitors: successes and failures. Anticancer Agents Med. Chem. 2007, 7, 171-188.

[18] Damm-Ganamet, K. L.; Bembenek, S. D.; Venable, J. W.; Castro, G. G.; Mangelschots, L.; Peeters, D. C.; Mcallister, H. M.; Edwards, J. P.; Disepio, D.; Mirzadegan, T. A prospective virtual screening study: enriching hit rates and designing focus libraries to find inhibitors of PI3K $\delta$ and PI3K $\gamma$ J. Med. Chem. 2016, 59, 4302-13.

[19] a) Canvas, Schrödinger, LLC, New York, NY, 2009. b) Chen, X.; Reynolds, C. H. Performance of similarity measures in 2D fragment-based similarity searching: comparison of structural descriptors and similarity coefficients J. Chem. Inf. Comput. Sci. 2002, 42, 1407-1414.

[20] Eckert, H.; Bajorath, J. Molecular similarity analysis in virtual screening: foundations, limitations and novel approaches. Drug Discov. Today 2007, 12, 225-33.

[21] a) Wale, N.; Watson, I. A.; Karypis, G. Indirect similarity based methods for effective scaffold-hopping in chemical compounds. J. Chem. Inf. Model. 2008, 48, 730-741. b) Broccatelli, F.; Brown, N. Best of both worlds: on the complementarity of ligand-based and structure-based virtual screening J. Chem. Inf. Model. 2008, 54, 1634-1641.

[22] Knowles, P. P.; Murray-Rust, J.; Kjaer, S.; Scott, R. P.; Hanrahan, S.; Santoro, M.; Ibanez, C. F.; Mcdonald, N. Q. Structure and chemical inhibition of the RET tyrosine kinase domain. J. Biol. Chem. 2006, 281, 33577-33587. 
[23] Perspicace, E.; Jouan-Hureaux, V.; Ragno, R.; Ballante, F.; Sartini, S.; La Motta, C.; Da Settimo, F.; Chen, B.; Kirsch, G.; Schneider, S.; Faivre, B.; Hesse, S. Design, synthesis and biological evaluation of new classes of thieno[3,2- $d]$ pyrimidinone and thieno[1,2,3]triazine as inhibitor of vascular endothelial growth factor receptor-2 (VEGFR-2). Eur. J. Med. Chem. 2013, $63,765-81$.

[24] La Motta, C.; Sartini, S.; Tuccinardi, T.; Nerini, E.; Da Settimo, F.; Martinelli, A. Computational studies of epidermal growth factor receptor: docking reliability, three-dimensional quantitative structure-activity relationship analysis, and virtual screening studies. J. Med. Chem. 2007, 52, 964-75.

[25] Sartini, S.; Coviello, V.; Bruno, A.; La Pietra, V.; Marinelli, L.; Simorini, F.; Taliani, S.; Salerno, S.; Marini, A. M.; Fioravanti, A.; Orlandi, P.; Antonelli, A.; Da Settimo, F.; Novellino, E.; Bocci, G.; La Motta, C. Structure-based optimization of tyrosine kinase inhibitor CLM3. Design, synthesis, functional evaluation, and molecular modeling studies. J Med Chem. 2014, 57, 1225-1235.

[26] Lanzi, C.; Cassinelli, G.; Nicolini, V.; Zunino, F. Targeting RET for thyroid cancer therapy. Biochem. Pharmacol. 2009, 77, 297-309.

[27] Song, S.; Ewald, A. J.; Stallcup, W.; Werb, Z.; Bergers, G. PDGFR $\beta+$ perivascular progenitor cells in tumours regulate pericyte differentiation and vascular survival. Nat. Cell Biol. 2005, 7, 870-879.

[28] Zabel, M.; Grzeszkowiak, J. Characterisation of thyroid medullary carcinoma TT cell line. Histol Histopathol. 1997, 12, 283-289.

[29] Bhal, S. K.; Kassam, K.; Peirson, I. G.; Pearl, G. M. The Rule of Five revisited: applying log D in place of $\log \mathrm{P}$ in drug-likeness filters. Mol Pharm. 2007, 4, 556-560.

[30] Broccatelli, F.; Mannhold, R.; Moriconi, A.; Giuli, S.; Carosati, E. QSAR modeling and data mining link torsades de pointes risk to the interplay of extent of metabolism, active transport, and hERG liability. Mol Pharm. 2012, Jul 13. 
[31] Chatal, J. F.; Kraeber-Bodéré, F.; Goldenberg, D. M.; Barbet, J. Treatment of metastatic medullary thyroid cancer with vandetanib: need to stratify patients on basis of calcitonin doubling time. J Clin Oncol. 2012, 30, 2165-2167.

[32] Yeung, K. S.; Farkas, M. E.; Kadow J. F.; Meanwell N. A. A base-catalyzed, direct synthesis of 3,5-disubstituted 1,2,4-triazoles from nitriles and hydrazides, Tetrahedron Lett. 2005, 46, 34293432.

[33] a) de Vicente, J.; Lemoine, R.; Bartlett, M.; Hermann, J. C.; Hekmat-Nejad, M.; Henningsen, R.; Jin, S.; Kuglstatter, A.; Li, H.; Lovey, A. J.; Menke, J.; Niu, L.; Patel, V.; Petersen, A.; Setti, L.; Shao, A.; Tivitmahaisoon, P.; Vu, M. D.; Soth, M. Scaffold hopping towards potent and selective JAK3 inhibitors: discovery of novel C-5 substituted pyrrolopyrazines. Bioorg. Med. Chem. Lett. 2014, 24, 4969-4975; b) Gustafson, W. C.; Meyerowitz, J. G.; Nekritz, E. A.; Chen, J.; Benes, C.; Charron, E.; Simonds, E. F.; Seeger, R.; Matthay, K. K.; Hertz, N. T.; Eilers, M.; Shokat, K. M.; Weiss, W. A. Drugging MYCN through an allosteric transition in aurora kinase A. Cancer Cell. 2014, 26, 414-427; c) Yin, Y.; Zheng, K.; Eid, N.; Howard, S.; Jeong, J. H.; Yi, F.; Guo, J.; Park, C. M.; Bibian, M.; Wu, W.; Hernandez, P.; Park, H.; Wu, Y.; Luo, J. L.; LoGrasso, P. V.; Feng, Y. Bis-aryl urea derivatives as potent and selective LIM kinase (Limk) inhibitors. $J$. Med. Chem. 2015, 58, 1846-1861.

[34] Allais, A.; Girault, P. $\beta$-(p-Chlorophenyl)propionic acid N2 isopropylhydrazide. FR146863, 1967.

[35] McGovern, S. L.; Caselli, E.; Grigorieff, N.; Shoichet, B. K. A common mechanism underlying promiscuous inhibitors from virtual and high-throughput screening. J. Med. Chem. 2002, 45, 1712-1722.

[36] Baldini, E.; Arlot-Bonnemains, Y.; Sorrenti, S.; Mian, C.; Pelizzo, M. R.; De Antoni, E.; Palermo, S.; Morrone, S.; Barollo, S.; Nesca, A.; Moretti, C. G.; D'Armiento, M.; Ulisse, S. Aurora kinases are expressed in medullary thyroid carcinoma (MTC) and their inhibition suppresses in 
vitro growth and tumorigenicity of the MTC derived cell line TT. BMC Cancer. 2011, 11, 411422.

[37] Antonelli, A.; Bocci, G.; La Motta, C.; Ferrari, S. M.; Fallahi, P.; Fioravanti, A.; Sartini, S.; Minuto, M.; Piaggi, S.; Corti, A.; Alì, G.; Berti, P.; Fontanini, G.; Danesi, R.; Da Settimo, F.; Miccoli, P. Novel pirazolopyrimidine derivatives as tyrosine kinase inhibitors with anti tumoral activity in vitro and in vivo in papillary dedifferentiated thyroid cancer. J Clin. Endocrinol. Metab. 2011, 96, E288-296.

[38] Antonelli, A.; Fallahi, P.; Ferrari, S. M.; Carpi, A.; Berti, P.; Materazzi, G.; Minuto, M.; Guastalli, M.; Miccoli, P. Dedifferentiated thyroid cancer: a therapeutic challenge. Biomed. Pharmacother. 2008, 62, 559-563.

[39] Antonelli, A.; Ferrari, S. M.; Fallahi, P.; Berti, P.; Materazzi, G.; Barani, L.; Marchetti, I.; Ferrannini, E.; Miccoli P. Primary cell cultures from anaplastic thyroid cancer obtained by fineneedle aspiration used for chemosensitivity tests. Clin. Endocrinol. 2008, 69, 148-152.

[40] Strock, C. J.; Park, J. I.; Rosen, D. M.; Ruggeri, B.; Denmeade, S. R.; Ball, D. W.; Nelkin, B. D. Activity of irinotecan and the tyrosine kinase inhibitor CEP-751 in medullary thyroid cancer. $J$ Clin. Endocrinol. Metab. 2006, 91, 79-84.

[41] Antonelli, A.; Ferrari, S. M.; Fallahi, P.; Berti, P.; Materazzi, G.; Marchetti, I.; Ugolini, C.; Basolo, F.; Miccoli, P.; Ferrannini, E. Evaluation of the sensitivity to chemotherapeutics or thiazolidinediones of primary anaplastic thyroid cancer cells obtained by fine-needle aspiration. Eur. J. Endocrinol. 2008, 159, 283-291.

[42] LigPrep, version 2.5, Schrödinger, LLC, New York, NY, 2011.

[43] Mologni, L.; Rostagno, R.; Brussolo, S.; Knowles, P. P.; Kjaer, S.; Murray-Rust, J.; Rosso, E.; Zambon, A.; Scapozza, L.; Mcdonald, N. Q.; Lucchini, V.; Gambacorti-Passerini, C. Synthesis, structure-activity relationship and crystallographic studies of 3-substituted indolin-2-one RET inhibitors. Bioorg. Med. Chem. 2010, 18, 1482-1496.

[44] Maestro, version 9.2, Schrödinger, LLC, New York, NY, 2011 
[45] Glide, version 5.7, Schrödinger, LLC, New York, NY, 2011.

[46] Friesner, R. A.; Murphy, R. B.; Repasky, M. P.; Frye, L. L.; Greenwood, J. R.; Halgren, T. A.; Sanschagrin, P.C.; Mainz, D.T. Extra precision glide: docking and scoring incorporating a model of hydrophobic enclosure for protein-ligand complexes, J. Med. Chem. 2006, 49, 61776196. 
Graphical Abstract

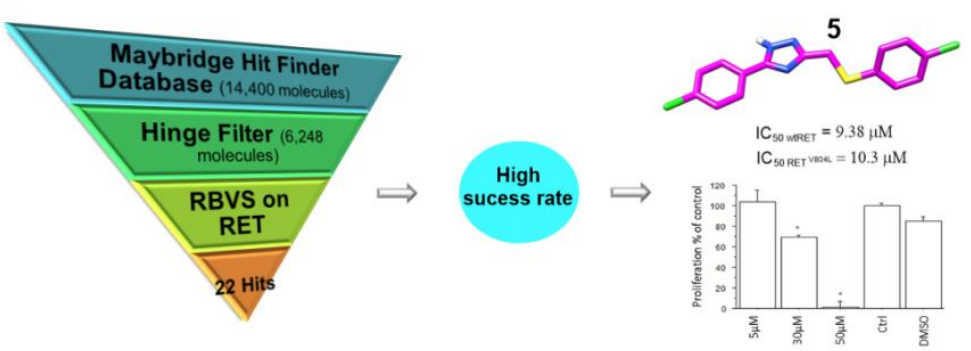

